\title{
Dielectric Relaxations in Poly(Glycidyl Phenyl Ether): Effects of Microstructure and Cyclic Topology
}

Thomas Gambino, ${ }^{a}$ Antxon Martínez de Ilarduya, ${ }^{b}$ Angel Alegría, a,c and Fabienne Barroso-Bujans ${ }^{\mathrm{a}, \mathrm{d},{ }^{*}}$

${ }^{a}$ Centro de Física de Materiales (CSIC, UPV/EHU) - Materials Physics Center. Paseo Manuel de Lardizabal 5, E-20018 San Sebastián, Spain

${ }^{b}$ Departament d'Enginyeria Química, Universitat Politècnica de Catalunya, ETSEIB, Diagonal 647, 08028 Barcelona, Spain

${ }^{c}$ Departamento de Física de Materiales, Universidad del País Vasco (UPV/EHU). Paseo Manuel de Lardizabal 3, E-20018 San Sebastián, Spain

${ }^{\mathrm{d}}$ Donostia International Physics Center (DIPC). Paseo Manuel de Lardizabal 4, E-20018 San Sebastián, Spain

*Corresponding author. E-mail address: fbarroso@ehu.eus (F. Barroso-Bujans) 


\section{ABSTRACT}

Cyclic and linear, isoregic and aregic, and isotactic and atactic poly(glycidyl phenyl ether) (PGPE) with molecular weights up to $\mathrm{M}_{\mathrm{w}}=5.5 \mathrm{~kg} / \mathrm{mol}$ are synthesized by ringopening polymerization of glycidyl phenyl ether. Initiation with tetrabutylammonium fluoride leads to isoregic linear polymers with $\sim 95 \%$ regular linkages, and initiation with $\mathrm{B}\left(\mathrm{C}_{6} \mathrm{~F}_{5}\right)_{3}$ and $\mathrm{B}\left(\mathrm{C}_{6} \mathrm{~F}_{5}\right)_{3} /$ water leads to aregic cyclic and linear polymers, respectively, with $\sim 50 \%$ regular linkages as quantified by ${ }^{13} \mathrm{C}$ NMR. Local, segmental, and chain dynamics in PGPE is investigated by broadband dielectric spectroscopy $\left(10^{-2}\right.$ $10^{6} \mathrm{~Hz}$ ). The $\beta$-relaxation for linear PGPE is separated into two contributions arising from the motions of side groups and end groups with activation energies of 35.4 and $23.8 \mathrm{~kJ} / \mathrm{mol}$, respectively. The $\beta$-relaxation process for cyclic PGPE shows the same activation energy as that shown by the side-group contribution in linear PGPE, indicating that topology does not play a key role on the side-group local dynamics. Moreover, cyclic PGPE samples show higher calorimetric and dynamic glass transition temperatures, as well as lower dynamic fragility compared to linear chains. Unexpectedly from topological considerations, cyclic PGPE shows low frequency dielectric contributions that can be attributed to short wavelength internal ring motions, and that are detectable by dielectric relaxation due to the aregic nature of the rings. 


\section{INTRODUCTION}

Physical properties of polymers are directly associated with the microstructure of the main chain, size, and chain topology. Cyclic polymers are a class of topological polymers characterized by the absence of chain ends. ${ }^{1}$ They exhibit increased glass transition temperatures $\left(T_{g}\right)$, smaller hydrodynamic volumes, and lower intrinsic viscosities when compared to their linear analogues. Such differences arise from the excess of mobility provided by end-groups in linear chains, the frustration of segmental rotational diffusion in small rings, and the much smaller configurational entropy of cyclic chains compared to their linear analogues. ${ }^{2}$ Detailed discussion of the physical and theoretical aspects of cyclic polymers has been reviewed elsewhere. ${ }^{3-6}$

Broadband dielectric spectroscopy (BDS) can be used to probe local, segmental and chain dynamics of polymers having dipole moment components either in the backbone or in the side group. ${ }^{7}$ Although this technique provides access to a large dynamic range, very few studies elucidating the effect of cyclic topology on the dynamics have been carried out by BDS, in comparison with other techniques much more utilized such as NMR ${ }^{8}$ rheology, ${ }^{9,10}$ and neutron diffraction techniques. ${ }^{5,11}$ Previous BDS study on the segmental dynamics of cyclic poly(dimethyl siloxane) (PDMS) was carried out by Krist et al. $^{2}$ They observed distinct molecular weight dependence of the $\alpha$-relaxation for cyclic and linear chains in agreement with a calorimetric study on similar polymer carried out by Semlyen et al. ${ }^{12}$ The $\alpha$-relaxation (glass transition temperature, $T_{g}$, in the work of Semlyen et al. ${ }^{12}$ ) of linear chains was observed to shift to lower temperatures with decreasing molecular weight, but for cyclic chains it was observed to shift to higher temperatures. 
Poly(glycidyl phenyl ether) (PGPE), a polyether with pendant methoxy phenyl groups, is characterized by large dipole moments. This polymer is able to crystallize when its side groups are ordered in a single orientation with respect to the polymer backbone; that is the isotactic form of PGPE. ${ }^{13}$ However, in its atactic form, PGPE is totally amorphous, making possible a complete characterization of its molecular dynamics in a broad range of temperatures without interference of crystallization. All these convenient characteristics provide an opportunity to investigate the influence of the chain topology and the microstructure on the polymer dynamics in a broad range of frequencies and temperatures.

Herein, we study the relaxation dynamics of cyclic and linear PGPE by means of BDS. Linear and cyclic PGPE exhibit three dielectric relaxations: $\beta$-relaxation, $\alpha$-relaxation and normal mode (NM). In general, the $\beta$-relaxation is related to a specific motion of a group of atoms, either in the polymer backbone, in the side groups and/or in the endgroups $;^{7}$ being the latter of relevance in this study. The $\alpha$-relaxation is originating from segmental-scale motions and the NM is originating from chain motions. ${ }^{7}$

The dielectric NM has been used to investigate chain dynamics and chain dimensions in polymers with complex architectures. ${ }^{14,15}$ Some examples include the study of the NM relaxation in star-branched polyisoprene (PI), ${ }^{16}$ star-branched polyisoprene-polystyrene (PI-PS) block copolymer, ${ }^{17}$ PI confined in nanometer-size pores, ${ }^{18}$ PI-PDMS block copolymers $^{19}$ and poly(alkylene oxide)s with side chains of different size. ${ }^{20}$ Cyclic polymers are expected to have net zero dipole moment due to cancellation of the dipole moment vectors parallel to the chain contour. However, this is only true for isoregic polymers, where all the repeating units are oriented in the same direction, but not for polymers containing regio-irregularities. 
Isoregic structures are generated by the formation of head-to-tail (HT) or tail-to-head (TH) linkages during polymerization, whereas aregic structures are generated by the additional formation of head-to-head (HH) and tail-to-tail (TT) linkages. In the ringopening polymerization (ROP) of monosubstituted epoxides, these regio-errors can frequently occur. ${ }^{21}$ Enchainment can be produced by (1) attack at the methylene, or (2) attack at the methine (Scheme 1). If only one process occurs, then an isoregic polymer is obtained. If both processes are produced, then an aregic polymer is obtained.

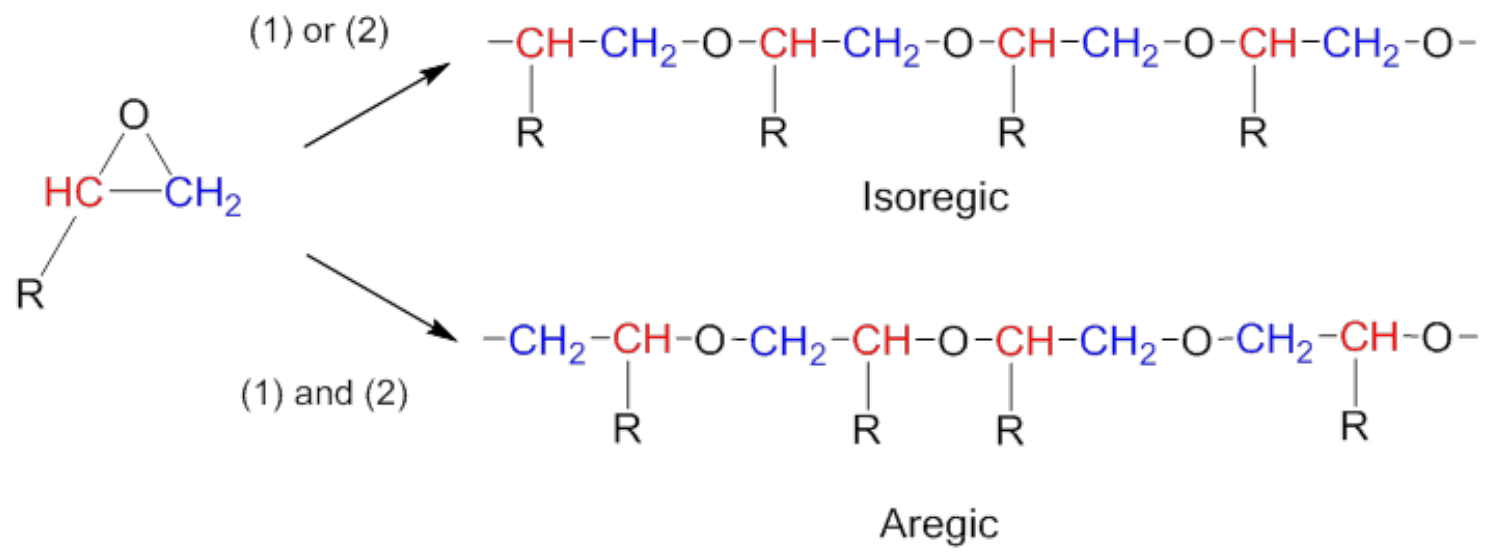

Scheme 1. Isoregic and aregic polyethers obtained by ring-opening polymerization of monosubstituted epoxides. Enchainment by attack at the methylene (1) and/or attack at the methine (2).

In the present study, cyclic PGPE is obtained by zwitterionic ring-opening polymerization (ZROP) of glycidyl phenyl ether (GPE) with a Lewis acid catalyst, $\mathrm{B}\left(\mathrm{C}_{6} \mathrm{~F}_{5}\right)_{3}$, in anhydrous conditions, ${ }^{22}$ utilizing what is called a ring-expansion polymerization strategy. ${ }^{23}$ Linear PGPE was obtaining by using two synthetic pathways: 1) ZROP of GPE with $\mathrm{B}\left(\mathrm{C}_{6} \mathrm{~F}_{5}\right)_{3}$, in the presence of water ${ }^{22}$ and 2) anionic ROP of GPE 
with a thermally latent anionic initiator, tetrabutylammonium fluoride (TBAF). ${ }^{24}$ Quantitative analysis of the microstructure by means of ${ }^{13} \mathrm{C}$ NMR shows that cyclic and linear PGPE obtained by ZROP contain high levels of regio-irregularities, whereas linear PGPE obtained by anionic ROP is almost isoregic. Moreover, in order to generate PGPE samples of different degrees of crystallinity, we also exerted some control over the stereochemistry by using optically pure (S)-GPE and a mixture of (S/R)-GPE enantiomers. Semicrystalline linear PGPE samples were obtained with (S)-GPE, whereas totally amorphous samples were obtained with the (S/R)-GPE enantiomers.

The provision of different types of PGPE samples in this work, linear and cyclic, isoregic and aregic, and isotactic and atactic, allowed us to study in detail the effects of microstructure and cyclic topology on the molecular mobility at different spatial scales by dielectric spectroscopy.

\section{EXPERIMENTAL SECTION}

Materials. $\mathrm{B}\left(\mathrm{C}_{6} \mathrm{~F}_{5}\right)_{3}(95 \%)$, optically pure (S)-GPE ( $\geq 97 \%$ sum of enantiomers, GC), a mixture of (S/R)-GPE enantiomers (99\% purity) and water (molecular biology reagent) were purchased from Sigma-Aldrich. GPE, dichloromethane $\left(\mathrm{CH}_{2} \mathrm{Cl}_{2}\right)$ and methanol were dried over $\mathrm{CaH}_{2}$, degassed and distilled in a vacuum line before use. $\mathrm{B}\left(\mathrm{C}_{6} \mathrm{~F}_{5}\right)_{3}$ was sublimed in vacuum at $90{ }^{\circ} \mathrm{C}$ and stored in a glovebox. All reagents were manipulated and transferred either by distillation or under argon in a vacuum line.

Synthesis of linear PGPE. Linear PGPE samples were synthesized by two methods, living anionic ROP (Method-A) and ZROP (Method-Z). Method-A was based on a method reported by Endo et al. ${ }^{24}$ and Method-Z was based on a method previously reported by us. ${ }^{22}$ To identify 
the different synthesized compounds, the following conventions are applied: $\mathrm{L}$ is assigned to linear samples and $\mathrm{C}$ to cyclic samples. As a subscript, $\mathrm{S}$ is assigned to polymers synthesized from optically pure (S)-GPE monomer, and SR, to those synthesized from (S/R)-GPE enantiomers. (A) is assigned to polymers synthesized by anionic ROP and (Z) to polymers synthesized by ZROP.

Method-A: (S)-GPE and (S/R)-GPE were polymerized by initiation with tetrabutylammonium fluoride (TBAF) (hereafter denoted as $\mathrm{L}_{\mathrm{S}}(\mathrm{A})$ and $\mathrm{L}_{\mathrm{SR}}(\mathrm{A})$ samples, Table 1). TBAF (1M) in THF solution $(0.7 \mathrm{~mL})$ was added to a Schlenk under Argon. THF was evaporated under vacuum, and GPE $(2 \mathrm{~mL})$ was added. The polymerization was conducted at $60{ }^{\circ} \mathrm{C}$ in argon. To generate PGPE samples of different molecular weights, the reaction time was varied from $15 \mathrm{~min}$ to $6 \mathrm{~h}$, or upon the addition of $2 \mathrm{~mL}$ extra of GPE after $6 \mathrm{~h}$ of reaction, according to reference 24 . The crude was dissolved in $\mathrm{CH}_{2} \mathrm{Cl}_{2}$ and precipitated in methanol. Precipitation was repeated until total disappearance of TBAF, as verified by ${ }^{1} \mathrm{H}$ NMR spectroscopy.

Method-Z: (S)-GPE and (S/R)-GPE were polymerized by initiation with a mixture of $\mathrm{B}_{\left(\mathrm{C}_{6} \mathrm{~F}_{5}\right)_{3}}$ and water (hereafter denoted as $\mathrm{L}_{\mathrm{S}}(\mathrm{Z})$ and $\mathrm{L}_{\mathrm{SR}}(\mathrm{Z})$ samples, Table 2$)$. $\mathrm{B}\left(\mathrm{C}_{6} \mathrm{~F}_{5}\right)_{3}(4 \mathrm{mg}), \mathrm{CH}_{2} \mathrm{Cl}_{2}(4$ $\mathrm{mL})$, water $(0.2 \mathrm{ml})$ and GPE $(1 \mathrm{~mL})$ were added (in this order) to a Schlenk flask under argon atmosphere. After $24 \mathrm{~h}$, the solvent was evaporated, and the remaining liquid (still not viscous) was heated for $24 \mathrm{~h}$ at $40{ }^{\circ} \mathrm{C}$. The crude was dissolved in $\mathrm{CH}_{2} \mathrm{Cl}_{2}$ and precipitated in methanol.

Synthesis of cyclic PGPE. Cyclic PGPE samples were synthesized by ZROP of (S)-GPE and (S/R)-GPE according to our previously published method ${ }^{22}$ (hereafter denoted as $\mathrm{C}_{\mathrm{S}}(\mathrm{Z})$ and $\mathrm{C}_{\mathrm{SR}}(\mathrm{Z})$ samples, Table 2). All polymerization reactions were performed under argon at room temperature. In a typical experiment, $\mathrm{B}\left(\mathrm{C}_{6} \mathrm{~F}_{5}\right)_{3}(4 \mathrm{mg}), \mathrm{CH}_{2} \mathrm{Cl}_{2}(10 \mathrm{~mL})$ and $\mathrm{GPE}(1 \mathrm{~mL})$ were added (in this order) to a Schlenk flask under argon atmosphere. After $24 \mathrm{~h}$ of reaction, $0.2 \mathrm{~mL}$ of dry methanol was added to the reaction. The solution was partially concentrated by removing 
half of the solvent mixture in the vacuum line. Finally, the polymer was precipitated in methanol.

All the PGPE samples were dried in a vacuum oven at $80^{\circ} \mathrm{C}$ overnight before use. Experimental procedures to chemically characterize the PGPE samples [MALDI-ToF MS, size exclusion chromatography (SEC) and ${ }^{13} \mathrm{C}$ NMR data] are reported in the Supplementary Information document.

Table 1. Linear PGPE samples obtained by living anionic ROP at $60{ }^{\circ} \mathrm{C}(\operatorname{Method}-A){ }^{24}$

\begin{tabular}{cccccc}
\hline Entry & Sample & Monomer & $\mathbf{M}_{\mathbf{w}}{ }^{\mathbf{b}}$ & $\mathbf{M}_{\mathbf{w}} / \mathbf{M}_{\mathbf{n}}{ }^{\mathbf{b}}$ & $\mathbf{Y i e l d ~}^{\mathbf{c}}$ \\
& & & $(\mathbf{k g} / \mathbf{m o l})$ & & $(\mathbf{\%})$ \\
\hline 1 & $\mathrm{~L}_{\mathrm{S}}(\mathrm{A})$ & (S)-GPE & 2.1 & 1.02 & 60 \\
2 & $\mathrm{~L}_{\mathrm{SR}}(\mathrm{A})$ & $(\mathrm{S} / \mathrm{R})-\mathrm{GPE}$ & 2.2 & 1.06 & 70 \\
3 & $\mathrm{~L}_{\mathrm{SR}}(\mathrm{A})$ & $(\mathrm{S} / \mathrm{R})-\mathrm{GPE}$ & 3.0 & 1.07 & 63 \\
$4^{\mathrm{a}}$ & $\mathrm{L}_{\mathrm{SR}}(\mathrm{A})$ & $(\mathrm{S} / \mathrm{R})-\mathrm{GPE}$ & 4.8 & 1.10 & 80
\end{tabular}

${ }^{\mathrm{a}} 2 \mathrm{~mL}$ of GPE were initially polymerized for $6 \mathrm{~h}$ followed by further addition of $2 \mathrm{~mL}$ of GPE. The reaction was stopped after $16 \mathrm{~h}$ of second monomer addition. ${ }^{\mathrm{b}}$ Obtained by SEC. ${ }^{\mathrm{c}}$ Obtained by weight of the precipitated products.

Table 2. Linear and cyclic PGPE samples obtained by ZROP at $25^{\circ} \mathrm{C}$ (Method-Z). ${ }^{22}$

\begin{tabular}{|c|c|c|c|c|c|c|c|c|}
\hline Entry & Sample & Monomer & $\begin{array}{c}\mathrm{n}(\mathrm{GPE}) / \\
\mathrm{n}\left[\mathrm{B}\left(\mathrm{C}_{6} \mathrm{~F}_{5}\right)_{3}\right] \\
(\mathrm{mol} / \mathrm{mol})\end{array}$ & $\begin{array}{c}\mathrm{c}(\mathrm{GPE})^{\mathrm{a}} \\
(\mathrm{mol} / \mathrm{L})\end{array}$ & $\begin{array}{l}\text { t } \\
\text { (h) }\end{array}$ & $\begin{array}{c}M_{w}^{c} \\
(\mathrm{~kg} / \mathrm{mol})\end{array}$ & $\begin{array}{l}\mathbf{M}_{\mathbf{w}} / \\
\mathbf{M}_{\mathbf{n}}^{\mathbf{c}}\end{array}$ & $\begin{array}{l}\text { Yield }^{\mathrm{d}} \\
(\mathrm{wt} \%)\end{array}$ \\
\hline \multicolumn{9}{|c|}{ Linear samples } \\
\hline 5 & $\mathrm{~L}_{\mathrm{S}}(\mathrm{Z})$ & (S)-GPE & 935 & 1.5 & $48^{b}$ & 2.1 & 1.02 & 65 \\
\hline 6 & $\mathrm{~L}_{\mathrm{SR}}(\mathrm{Z})$ & (S/R)-GPE & 94 & 2.4 & $48^{\mathrm{b}}$ & 1.3 & 1.03 & 60 \\
\hline 7 & $\mathrm{~L}_{\mathrm{SR}}(\mathrm{Z})$ & (S/R)-GPE & 935 & 2.4 & $48^{\mathrm{b}}$ & 5.5 & 1.22 & 62 \\
\hline
\end{tabular}




\begin{tabular}{|c|c|c|c|c|c|c|c|c|}
\hline \multicolumn{9}{|c|}{ Cyclic samples } \\
\hline 8 & $\mathrm{C}_{\mathrm{S}}(\mathrm{Z})$ & (S)-GPE & 935 & 0.4 & 24 & 1.9 & 1.30 & 53 \\
\hline 9 & $\mathrm{C}_{\mathrm{SR}}(\mathrm{Z})$ & (S/R)-GPE & 935 & 0.4 & 24 & 1.4 & 1.26 & 50 \\
\hline 10 & $\mathrm{C}_{\mathrm{SR}}(\mathrm{Z})$ & $(\mathrm{S} / \mathrm{R})-\mathrm{GPE}$ & 752 & 0.6 & 24 & 5.2 & 1.23 & 48 \\
\hline
\end{tabular}

${ }^{\mathrm{a}}$ Monomer concentration in $\mathrm{CH}_{2} \mathrm{Cl}_{2} \cdot{ }^{\mathrm{b}} 24 \mathrm{~h}$ at $25^{\circ} \mathrm{C}$ followed by solvent evaporation and heating at $40{ }^{\circ} \mathrm{C}$ for further $24 \mathrm{~h} .{ }^{\circ}$ Obtained by SEC. ${ }^{\mathrm{d}}$ Obtained by weight of the precipitated products.

Differential Scanning Calorimetry. DSC measurements were carried out on $\sim 5 \mathrm{mg}$ specimens using a Q2000 TA Instruments in standard mode. All samples were measured by placing the samples in sealed aluminum pans, cooling to $-100{ }^{\circ} \mathrm{C}$ at $20{ }^{\circ} \mathrm{C} / \mathrm{min}$ and heating to $150{ }^{\circ} \mathrm{C}$ at 20 ${ }^{\circ} \mathrm{C} / \min \left(1^{\text {st }}\right.$ run $)$. Then, samples were cooled back to $-100{ }^{\circ} \mathrm{C}$ at $20{ }^{\circ} \mathrm{C} / \mathrm{min}\left(2^{\text {nd }}\right.$ run $)$, and finally heated to $150{ }^{\circ} \mathrm{C}$ at $20{ }^{\circ} \mathrm{C} / \mathrm{min}\left(3^{\text {rd }}\right.$ run $)$. $\mathrm{L}_{\mathrm{s}}(\mathrm{A})$ was also measured by following a quenching protocol. The sample was first molten at $150{ }^{\circ} \mathrm{C}$, then cooled at the highest cooling ramp attainable by the equipment, and heated back to $150{ }^{\circ} \mathrm{C}$ at $20^{\circ} \mathrm{C} / \mathrm{min}$. A helium flow rate of 25 $\mathrm{mL} / \mathrm{min}$ was used throughout.

Broadband dielectric spectroscopy. A broadband and high-resolution dielectric spectrometer, Novocontrol Alpha, was used to measure the complex dielectric function, $\varepsilon^{*}(\omega)=\varepsilon^{\prime}(\omega)-i \varepsilon$ " $(\omega), \omega=2 \pi f$, in the frequency $(f)$ range from $f=10^{-2} \mathrm{~Hz}$ to $f=10^{6} \mathrm{~Hz}$. Samples were placed between parallel gold-plated electrodes with $20 \mathrm{~mm}$ diameter and $0.1 \mathrm{~mm}$ thick, by using finely cut $0.1 \mathrm{~mm}$ thick cross-shaped Teflon as spacer. To remove the water traces, the samples were heated within the cell at $420 \mathrm{~K}$ for 1-2 h until constant conductivity. The data were collected isothermally during cooling from $420 \mathrm{~K}$ to $130 \mathrm{~K}$. The temperature was controlled within \pm 0.1 K using a Novocontrol Quatro cryostat that uses a continuous nitrogen-jet flow.

\section{RESULTS}


Enantiopure (S)-GPE and a mixture of (S/R)-GPE enantiomers were polymerized with TBAF, $\mathrm{B}\left(\mathrm{C}_{6} \mathrm{~F}_{5}\right)_{3} / \mathrm{H}_{2} \mathrm{O}$ or $\mathrm{B}\left(\mathrm{C}_{6} \mathrm{~F}_{5}\right)_{3}$ as a catalyst (Scheme 2 ). The first two catalysts lead to the generation of linear $\mathrm{PGPE}^{22,24}$ and the third one to the generation of cyclic PGPE. ${ }^{22}$ End groups of linear PGPE synthesized with TBAF and $\mathrm{B}\left(\mathrm{C}_{6} \mathrm{~F}_{5}\right)_{3} / \mathrm{H}_{2} \mathrm{O}$ differ in composition. In the first case, linear chains terminate with a fluorine atom and a hydroxyl group, and in the second case, terminate with two hydroxyl groups (see MALDI-TOF data in the Supplementary Information). Stereo- and regiochemistry of synthesized PGPE were also found to be different. PGPE obtained by initiation with TBAF are almost isoregic whereas those obtained with $\mathrm{B}\left(\mathrm{C}_{6} \mathrm{~F}_{5}\right)_{3}$ are aregic. Scheme 2 summarizes the main chemical and physical characteristics of the obtained polymers, which are described in detail in the following sections.

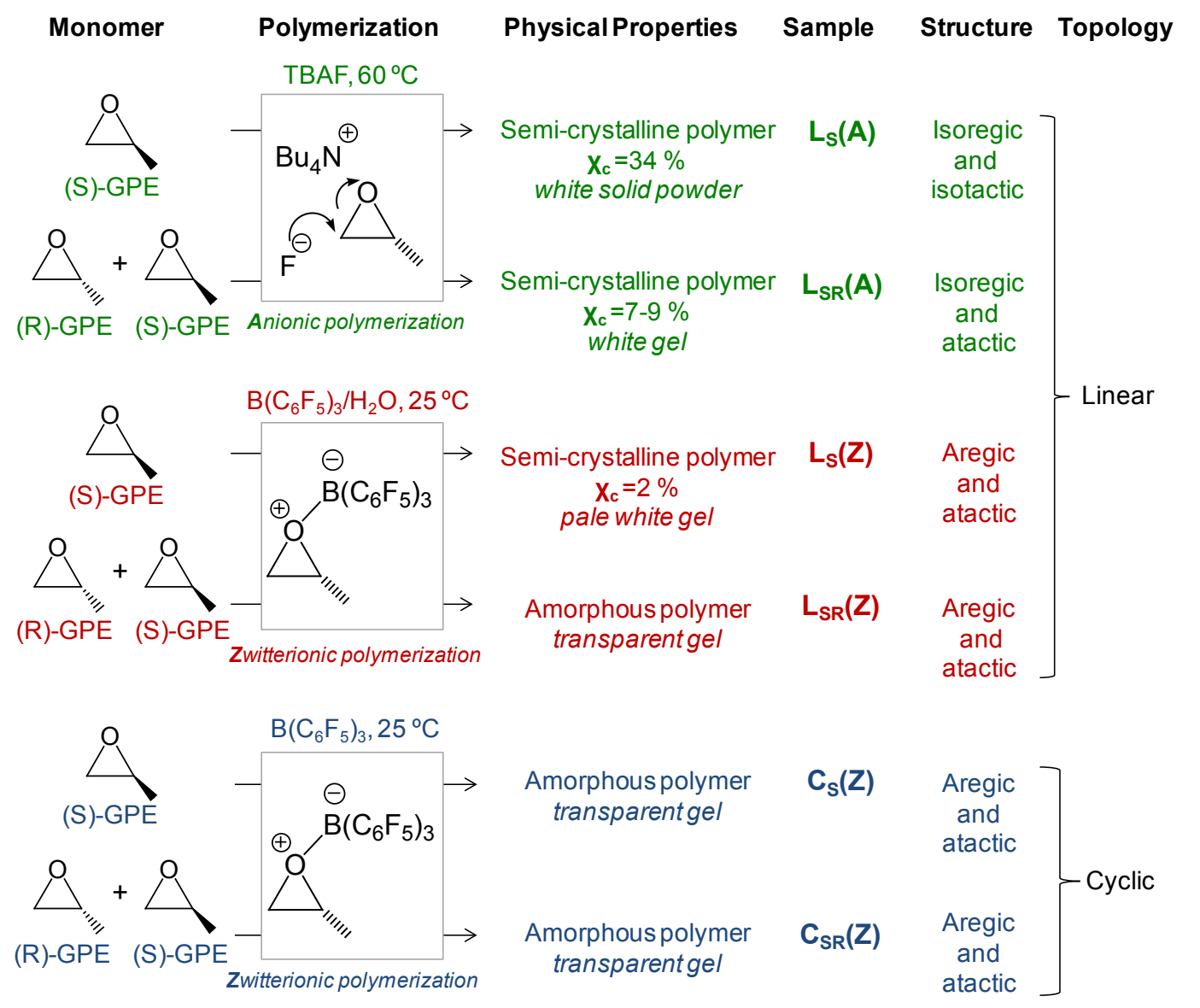


Scheme 2. Topology, microstructure and physical properties of PGPE obtained from enantiopure (S)-GPE and a mixture of (S/R)-GPE enantiomers via anionic and zwitterionic ROP.

\section{Polymer Microstucture by ${ }^{13} \mathrm{C}$ NMR Spectroscopy}

Analysis of polymer microstucture was done by ${ }^{13} \mathrm{C}$ NMR with the help of previously published data on the microstructure of PGPE. ${ }^{25}$ Figure 1 shows ${ }^{13} \mathrm{C}$ NMR spectra of linear PGPE samples in acetone- $d_{6}$, to which small amounts of trichloroacetyl isocyanate (TAI) derivatizing reagent were added. Upon the addition of TAI, the terminal hydroxyl groups are converted into urethane groups. The ${ }^{13} \mathrm{C}$ NMR signals of carbons in $\alpha$ and $\beta$ positions to the urethane groups appear downfield and upfield shifted, respectively, allowing an exhaustive identification of end-groups and consequently, allowing the identification of signals corresponding only to the polymer backbone.

Signals at $\sim 79.1 \mathrm{ppm}$ correspond to methine carbons, and are sensitive to triad regiosequence arrangements. Signals at $\sim 71.5 \mathrm{ppm}$ correspond to methylene carbons of the main chain, and are also sensitive to triad regiosequence distribution. Signals at 69 ppm corresponds to methylene carbons of the side chain, and are little sensitive to tacticity or regicity. Assignment of terminal groups, as well as of the different triad regiosequences generated by $\mathrm{HH}, \mathrm{HT}, \mathrm{TH}$ and TT linkages are indicated in the spectra. $\mathrm{Ls}(\mathrm{A})$ and $\mathrm{L}_{\mathrm{SR}}(\mathrm{A})$ exhibit high intensity signals corresponding to regio-regular triads with $[000,111]$ configurations produced by all HT or TH linkages (Scheme S1). These samples also exhibit the presence of signals of lower intensity corresponding to regio- 
irregular triads with [001, 011] configurations produced by HT, HT and TT or by HT, TH and TH linkages, as well as others signals corresponding to end-groups (Figure S4). This assignment differs to the one in reference 25 , and is based on the type of end groups observed in the NMR spectra for these samples, where no $\mathrm{CH}_{2} \mathrm{OH}$ end-group was observed and excludes the presence of $\mathrm{HH}$ linkages. In the $\mathrm{Ls}(\mathrm{Z})$ and $\mathrm{L}_{\mathrm{SR}}(\mathrm{Z})$ samples, it is remarkable the presence of signals corresponding to all kind of aregic sequences: $[010,101],[001,011]$ and $[100,110]$. Assignment of methylene signal corresponding to triad $[100,110]$ is based on the shielding effect produced by one additional carbon in gamma position for this triad, and the peak that appears downfield shifted at $72.4 \mathrm{ppm}$ was then assigned to $[010,101]$ triad.

Integration of triad signals and quantification of the amounts of regio-irregular linkages are reported in Table 3 . As a result, we obtained that the polymerization mediated by TBAF leads to a high level of regio-regularity (95-97\% of regio-regular linkages) and to a high level of tacticity when the optically pure (S)-GPE monomer is employed. The use of a mixture of (S/R)-GPE enantiomers leads to polymers with similar regioregularity but with an atactic stereoregularity (Figure S5). In contrast, the polymerization mediated by $\mathrm{B}\left(\mathrm{C}_{6} \mathrm{~F}_{5}\right)_{3}$, either in anhydrous or dry conditions, leads to a high level of regio-irregularity, and as a consequence, to the generation of aregic polymers. 


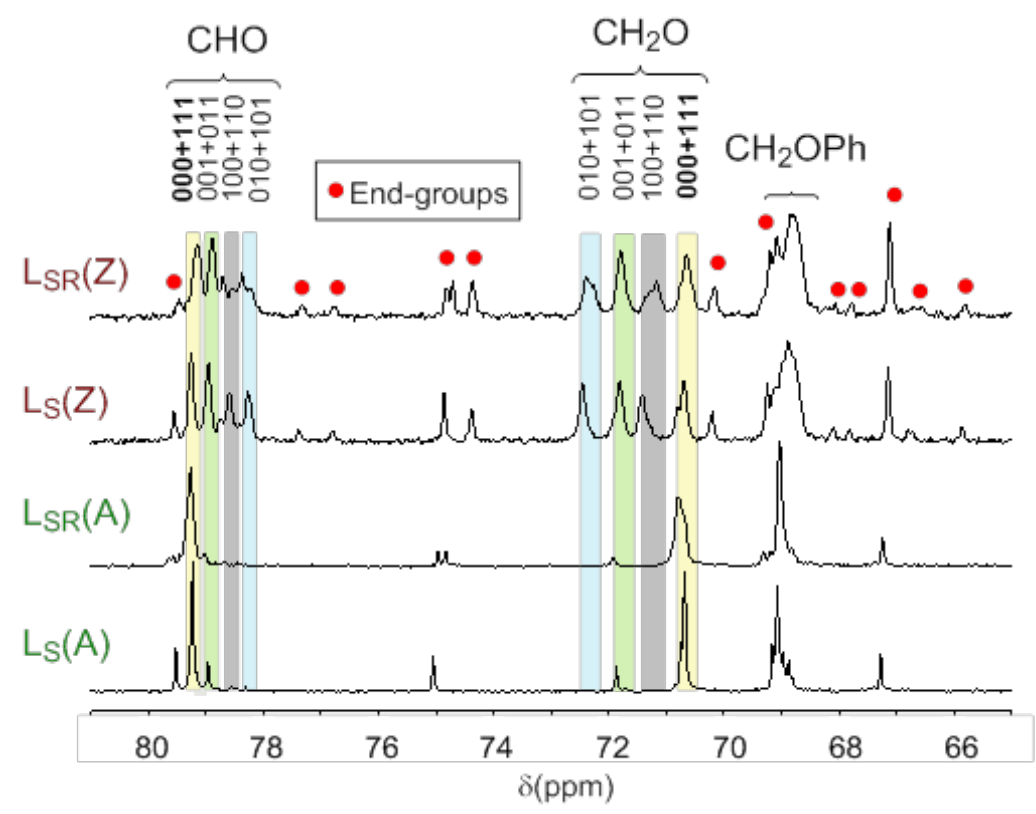

Figure 1. ${ }^{13} \mathrm{C}$ NMR spectra of PGPE samples in $\left(\mathrm{CD}_{3}\right)_{2} \mathrm{CO}$ at $25{ }^{\circ} \mathrm{C}$ upon the addition of TAI (Entries 1 and 2 of Table 1 and Entries 5 and 6 of Table 2). $L_{S}(A)$ sample was recorded at $50{ }^{\circ} \mathrm{C}$ due to solubility problems at room temperature.

Table 3. Percentage of regiosequences and amounts of regio-irregularities as obtained in $\left(\mathrm{CD}_{3}\right)_{2} \mathrm{CO}$ upon the addition of trichloroacetyl isocyanate derivatizing agent.

\begin{tabular}{|c|c|c|c|c|c|c|}
\hline \multirow[t]{2}{*}{ Entry } & \multirow[t]{2}{*}{ Sample } & \multicolumn{4}{|c|}{ Triads (mol\%) } & \multirow[t]{2}{*}{ Irregular linkages $(\%)$} \\
\hline & & $000-111$ & $001-011$ & $100-110$ & $010-101$ & \\
\hline 1 & $\mathrm{~L}_{\mathrm{S}}(\mathrm{A})$ & 93.7 & 6.3 & - & - & 3.1 \\
\hline 2 & $\mathrm{~L}_{\mathrm{SR}}(\mathrm{A})$ & 89.7 & 10.3 & - & - & 5.1 \\
\hline 5 & $\mathrm{~L}_{\mathrm{S}}(\mathrm{Z})$ & 27.9 & 27.0 & 21.7 & 23.4 & 47.7 \\
\hline 6 & $\mathrm{~L}_{\mathrm{SR}}(\mathrm{Z})$ & 30.6 & 27.5 & 20.3 & 21.6 & 45.5 \\
\hline 10 & $\mathrm{C}_{\mathrm{SR}}(\mathrm{Z})$ & 24.3 & 25.8 & 20.1 & 29.8 & 52.7 \\
\hline
\end{tabular}


End-group analysis by ${ }^{13} \mathrm{C}$ NMR indicates that PGPE samples initiated by TBAF [L(A) series] terminate with $\mathrm{CHOH}$ and $\mathrm{CH}_{2} \mathrm{~F}$ groups and does not show the presence of $\mathrm{CH}_{2} \mathrm{OH}$ terminal groups. In the PGPE samples initiated by $\mathrm{B}\left(\mathrm{C}_{6} \mathrm{~F}_{5}\right)_{3} / \mathrm{H}_{2} \mathrm{O}[\mathrm{L}(\mathrm{Z})$ series], the majority of end groups were found to be $\mathrm{CHOH}$. Minor amounts of $\mathrm{CH}_{2} \mathrm{OH}$ were also found.

\section{Crystallinity}

The degree of crystallinity $\left(\chi_{C}\right)$ of $\mathrm{L}_{\mathrm{S}}(\mathrm{A})$ was determined to be $34 \%$ by XRD (Figure S6). This is the most crystalline sample of the studied series as expected from its high level of both regicity and tacticity. In contrast to the rest of samples, its physical appearance is a solid powder, which is a qualitative indication of crystallinity. DSC data of $\mathrm{L}_{\mathrm{S}}(\mathrm{A})$ (Figure $2 \mathrm{a}$ ) shows four melting processes $\left(\mathrm{T}_{\mathrm{m} 1}, \mathrm{~T}_{\mathrm{m} 2}, \mathrm{~T}_{\mathrm{m} 3}\right.$ and $\left.\mathrm{T}_{\mathrm{m} 4}\right)$, which have been interpreted as to be originating from different isomorphic crystallites in isoregic and isotactic PGPE. ${ }^{13} \mathrm{~L}_{\mathrm{S}}(\mathrm{A})$ crystallizes at $55^{\circ} \mathrm{C}$ upon cooling at $20{ }^{\circ} \mathrm{C} / \mathrm{min}$ (Figure 2a). After being quenched from the melt, $\mathrm{L}_{S}(\mathrm{~A})$ shows a cold crystallization peak at $60{ }^{\circ} \mathrm{C}$ at a heating rate of $20^{\circ} \mathrm{C} / \mathrm{min}$ (Figure $2 \mathrm{~d}$ ). 

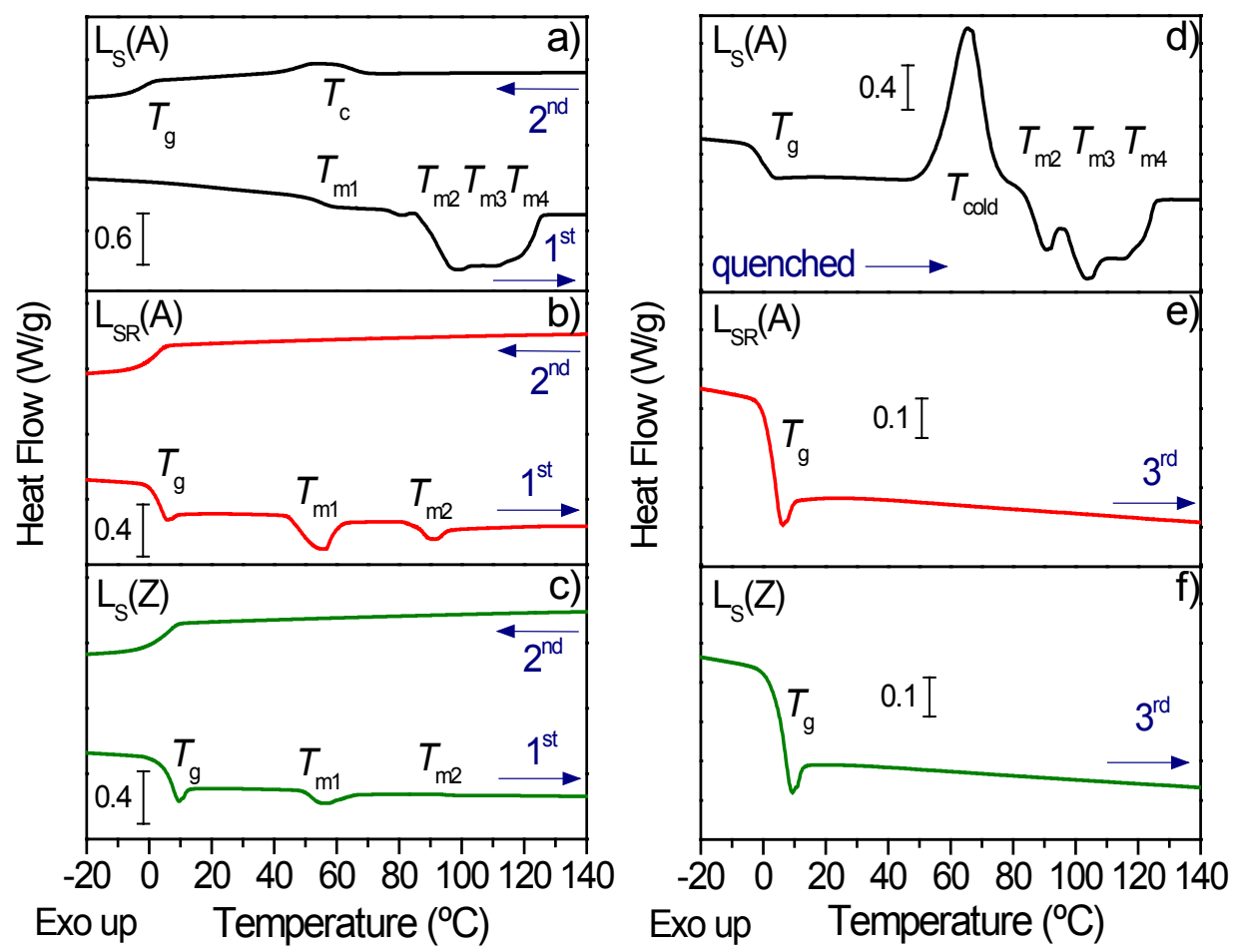

Figure 2. DSC data of semicrystalline PGPE samples: Entries 1, 2 of Table 1 and Entry 7 of Table $2 .(\mathrm{a}, \mathrm{b}, \mathrm{c}) 1^{\text {st }}$ and $2^{\text {nd }}$ runs $\left(20^{\circ} \mathrm{C} / \mathrm{min}\right)$ of samples previously cooled at -100 ${ }^{\circ} \mathrm{C}$ from room temperature. (d) Heating run $\left(20^{\circ} \mathrm{C} / \mathrm{min}\right)$ for a quenched $\mathrm{L}_{\mathrm{S}}(\mathrm{A})$ sample. (e) and (f) $3^{\text {rd }}$ heating runs $\left(20^{\circ} \mathrm{C} / \mathrm{min}\right)$ after cooling in experiments (b) and (c), respectively.

In contrast to DSC data of $\mathrm{L}_{S}(\mathrm{~A})$, the $\mathrm{L}_{\mathrm{SR}}(\mathrm{A})$ and $\mathrm{L}_{\mathrm{S}}(\mathrm{Z})$ samples showed two small melting processes and did not crystallize upon cooling (Figures $2 \mathrm{~b}$ and $2 \mathrm{c}$ ). As observed, $3^{\text {rd }}$ heating runs in $\mathrm{L}_{\mathrm{SR}}(\mathrm{A})$ and $\mathrm{L}_{\mathrm{S}}(\mathrm{Z})$ samples (Figures $2 \mathrm{e}$ and $2 \mathrm{f}$ ) do not show any sign of melting either. Crystallization in these samples occurs very slowly, in approximately two days at $40{ }^{\circ} \mathrm{C}$. This slow crystallization facilitates the study of fully 
amorphous samples. $\Delta \mathrm{H}_{\mathrm{m}}$ values of $\mathrm{L}_{\mathrm{SR}}(\mathrm{A})$ samples were observed to increase slightly with the molecular weight (Table 4).

Table 4. Crystallization/melting characteristics obtained from the DSC data of semicrystalline PGPE samples.

\begin{tabular}{|c|c|c|c|c|c|c|c|c|}
\hline Entry & Sample & $\begin{array}{c}\mathbf{T}_{\mathrm{c}} \\
\left({ }^{\circ} \mathrm{C}\right)\end{array}$ & $\begin{array}{l}\mathrm{Tm}_{1} \\
\left({ }^{\circ} \mathrm{C}\right)\end{array}$ & $\begin{array}{l}\mathbf{T m}_{2} \\
\left({ }^{\circ} \mathrm{C}\right)\end{array}$ & $\begin{array}{l}\mathrm{Tm}_{3} \\
\left({ }^{\circ} \mathrm{C}\right)\end{array}$ & $\begin{array}{l}\mathrm{Tm}_{4} \\
\left({ }^{\circ} \mathrm{C}\right)\end{array}$ & $\begin{array}{l}\Delta \mathbf{H}_{\mathrm{m}} \\
(\mathrm{J} / \mathrm{g})\end{array}$ & $\begin{array}{c}\chi_{c} \\
(\%)\end{array}$ \\
\hline 1 & $\mathrm{~L}_{\mathrm{S}}(\mathrm{A})$ & 55 & 60 & 96 & 108 & 120 & 64 & $34^{\mathrm{a}}$ \\
\hline 2 & $\mathrm{~L}_{\mathrm{SR}}(\mathrm{A})$ & - & 55 & 91 & - & - & 13 & $7^{\mathrm{b}}$ \\
\hline 3 & $\mathrm{~L}_{\mathrm{SR}}(\mathrm{A})$ & - & 53 & - & 105 & - & 14 & $8^{\mathrm{b}}$ \\
\hline 4 & $\mathrm{~L}_{\mathrm{SR}}(\mathrm{A})$ & - & 52 & - & 105 & - & 16 & $9^{b}$ \\
\hline 5 & $\mathrm{~L}_{\mathrm{S}}(\mathrm{Z})$ & - & 55 & 96 & - & - & 4 & $2^{\mathrm{b}}$ \\
\hline
\end{tabular}

${ }^{a}$ Determined by XRD and used as a reference for the rest of samples. ${ }^{b}$ Determined from the $\Delta \mathrm{H}_{\mathrm{m}}$ values.

The degree of crystallinity of $L_{S R}(A)$ and $L_{S}(Z)$ samples was determined from the $\Delta H_{m}$ values, estimating that $100 \%$ of crystallinity corresponds to $\Delta \mathrm{H}_{\mathrm{m}}=188 \mathrm{~J} / \mathrm{g}$, as obtained from XRD and DSC analysis of $L_{S}(A)$. As a result, $\chi_{C}$ of $L_{S R}(A)$ was $7-9 \%$, whereas that of $L_{S}(Z)$ was only $2 \%$.

As observed in our PGPE samples, crystallinity is notably reduced in going from $\mathrm{L}_{\mathrm{S}}(\mathrm{A})$ to $\mathrm{L}_{\mathrm{SR}}(\mathrm{A})$ as a consequence of the loss of tacticity while keeping similar regicity. Crystallinity is further reduced in going from $L_{S R}(A)$ to $L_{S}(Z)$ as a consequence of an 
increase of regio-irregularities. However, in spite of the significant amounts of regioirregular linkages in $\mathrm{L}_{\mathrm{S}}(\mathrm{Z})$, this sample is the only one of the whole polymer series obtained by ZROP that is able to crystallize, probably due to the presence of small isotactic sequences in the chain. Interestingly, $\mathrm{C}_{\mathrm{S}}(\mathrm{Z})$, with similar stereo- and regiochemistry to $\mathrm{L}_{S}(Z)$, did not show any sign of crystallization. It is likely that structural constraints due to the cyclic chain topology of $\mathrm{C}_{S}(Z)$ limit the formation of crystals, which is even more critical at the low levels of crystallinity shown by our samples. Distinctive crystallization behavior has been previously observed for cyclic polytetrahydrofuran (PTHF), ${ }^{26}$ and cyclic poly(e-caprolactone $)^{27,}{ }^{28}$ compared to their linear counterparts, although with opposite results: cyclic PTHF crystallized at a slower rate than the linear analog and cyclic poly(E-caprolactone) crystallized at a faster rate than the linear analog.

\section{Glass transition temperature}

Glass transition temperature of amorphous PGPE (obtained in all cases from (S/R)-GPE monomer) are plotted as a function of the molecular weight in Figure 3. In linear PGPE samples of the series $\mathrm{L}_{\mathrm{SR}}(\mathrm{A})$, the molecular weight dependence of the glass transition temperature can be described by the Kanig-Ueberreiter equation, ${ }^{29}$

$$
T_{g}=\left[\frac{1}{T_{g}^{\infty}}+\frac{K}{M_{w}}\right]^{-1}
$$

where $K$ was found to be $2.3 \times 10^{-4} \mathrm{~mol} / \mathrm{kg}$, and the high molecular weight limiting value, $T_{g}^{\infty}=282 \mathrm{~K} . T_{g}$ of $\mathrm{L}_{\mathrm{SR}}(\mathrm{Z})$ samples were in good agreement with the fitted curve. 
Cyclic PGPE samples showed higher $T_{g}$ than linear samples, as expected in the low molecular weight region. ${ }^{6}$ This behavior has been found in other cyclic polymers such as PDMS, ${ }^{12}$ polystyrene (PS), ${ }^{30,31}$ poly(2-vinylpyridine), ${ }^{32}$ poly(methyl methacrylate) ${ }^{33}$ poly(phenylmethylsiloxane) $)^{34}$ as well as in multicyclic topologies. ${ }^{35}$ Moreover, cyclic PGPE samples exhibited a weaker increase in $T_{g}$ with increasing molecular weight compared to their linear counterparts in agreement with the results found for PS in reference 36 . On the contrary, decreasing $T_{g}$ with increasing $\mathrm{M}_{\mathrm{w}}$ has been found for cyclic PDMS ${ }^{12}$ in agreement with theoretical predictions. ${ }^{37}$

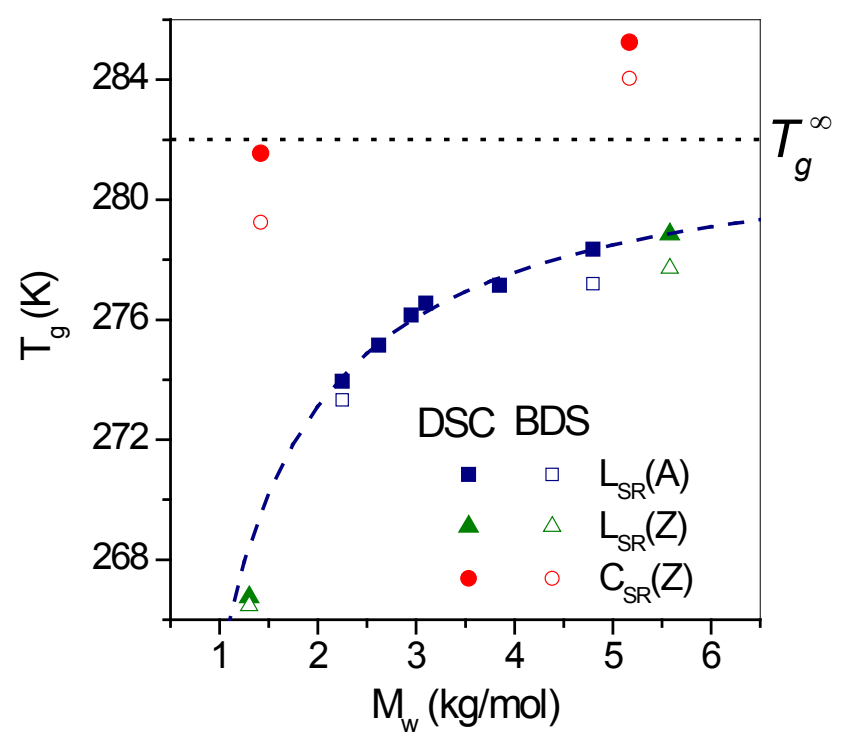

Figure 3. Solid symbols: Calorimetric onset $T_{g}$ data of PGPE samples as a function of the weight average molecular weight. $T_{g}$ values of all PGPE samples were obtained from the $3^{\text {rd }}$ heating runs. Dashed blue line represents the fit to Equation 1. Dotted black line shows the high molecular weight limiting value, $T_{g}{ }^{\infty}$, found for the $\mathrm{L}_{\mathrm{SR}}(\mathrm{A})$ series. Open symbols: Dielectric $T_{g}$ data $\left(T_{g}^{B D S}\right.$ ) (see the text below). 


\section{Dielectric Relaxations}

Figure 4a shows an isochronal representation of $\varepsilon$ " for two $L_{S R}(A)$ samples of different molecular weight, which were firstly dried for $1-2$ hours at $420 \mathrm{~K}$ within the equipment and subsequently cooled to $130 \mathrm{~K}$ by registering isothermically the dielectric spectra every $5 \mathrm{~K}$. Under these experimental conditions, completely dry samples can be measured in amorphous state. We rigorously checked that the relaxation peak associated with water had been removed (Figure S7). In Figure 4a, the loss peaks appearing above $\sim 274 \mathrm{~K}$ are assigned to the $\alpha$-relaxation and NM relaxation in agreement with previous dielectric relaxation studies of polyethers with pendant aliphatic ether groups such as poly(isopropyl glycidyl ether), poly( $n$-butyl glycidyl ether) and poly(tert-butyl glycidyl ether). ${ }^{38}$ The $\alpha$-relaxation peak shows a small shift to higher temperatures with the molecular weight, in agreement with the $T_{g}$ differences observed by DSC. The NM peak shows stronger molecular weight dependence, as expected, exhibiting a well-defined peak for the higher molecular weight sample, but strong overlapping with the $\alpha$ relaxation peak for the lower molecular weight sample. The loss peak appearing at temperatures well below $T_{g}$ is designated as $\beta$-relaxation. This relaxation process has been identified in reference 38 as originating from side group rotations. In our PGPE samples, the $\beta$-relaxation peak appears at higher temperatures than that in polyethers with pendant aliphatic ether groups, ${ }^{38}$ likely due to the bulkier nature of the phenyl side group. The $\beta$-relaxation also shows molecular weight dependence as observed by a decrease of intensity with increasing molecular weight at the low temperature side. 

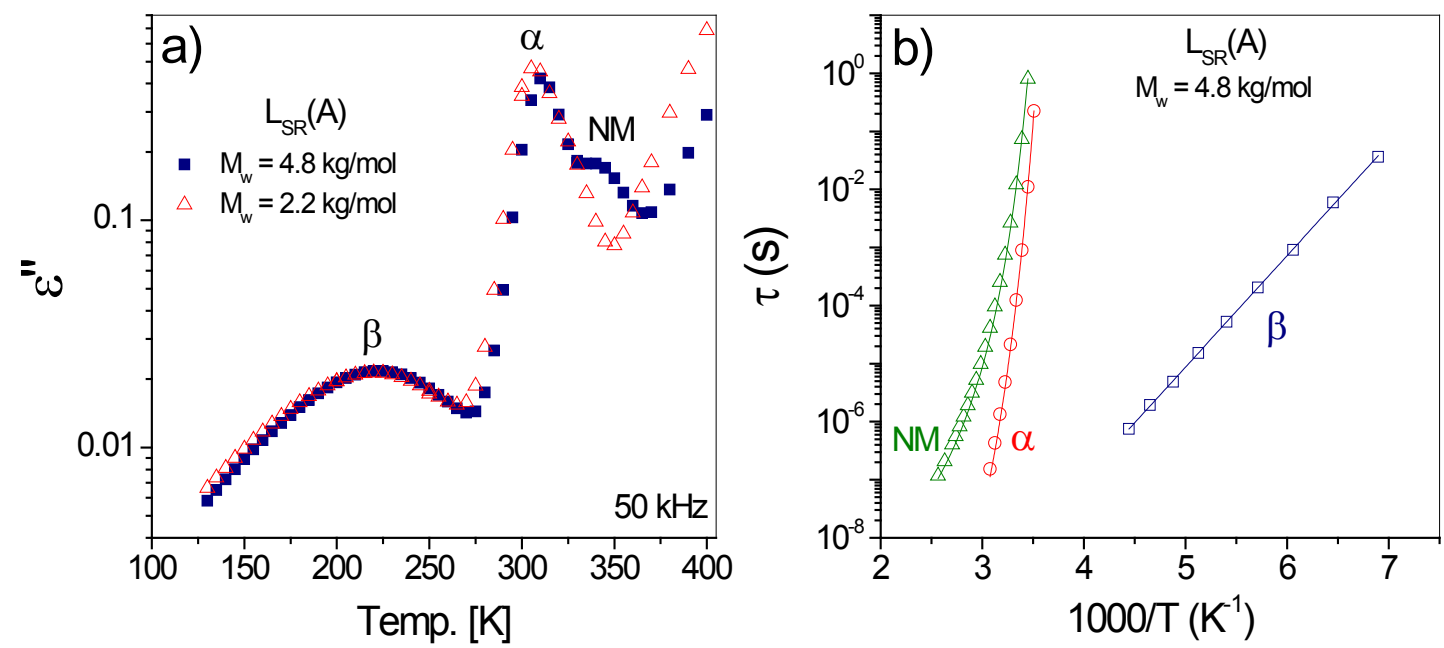

Figure 4. a) Isochronal representation of the dielectric loss ( $\left.\varepsilon^{\prime \prime}\right)$ at $50 \mathrm{kHz}$ for two $\mathrm{L}_{\mathrm{SR}}$ (A) samples of different molecular weight. b) Relaxation map for $L_{S R}(A)$ with $M_{w}=4.8$ $\mathrm{kg} / \mathrm{mol}$.

The peak relaxation times $(\tau)$ of the three dielectric relaxations observed for a $L_{S R}(A)$ sample are plotted as a function of the inverse temperature in Figure $4 \mathrm{~b}$. The $\beta$ relaxation shows Arrhenius temperature dependence, whereas the $\alpha$-relaxation and the NM show the typical non-Arrhenius behavior. Moreover, the $\alpha$-relaxation and the NM differ in the temperature dependence, being more separated at high temperatures.

The three dielectric relaxations here described are analyzed in detail in the following sections. 


\section{Dielectric relaxations at $T<T_{g}$}

Figure 5a shows the frequency dependence of the $\varepsilon$ " for $\mathrm{L}_{\mathrm{SR}}(\mathrm{A})$ of two molecular weights at $170 \mathrm{~K}$. At the high frequency side, the spectra show decreasing intensity with increasing molecular weight, which is undoubtedly attributed to the contributions of end-group motions. At increasing molecular weights, the chain ends become more diluted and their contribution to the $\beta$-relaxation is mitigated. To resolve the component peaks of the $\beta$-relaxation coming from end-groups $\left(\varepsilon{ }^{\prime}{ }_{E G}(\omega)\right)$ and side-groups $\left(\varepsilon{ }^{\prime}{ }_{M w \rightarrow \infty}\right.$ $(\omega)$ ), we assumed that, for a given $\mathrm{M}_{\mathrm{w}}, \varepsilon{ }^{\prime}{ }_{\mathrm{Mw}}(\omega)$ can be expressed as:

$$
\varepsilon^{\prime \prime}{ }_{M w}(\omega)=\frac{2 m_{E G}}{M w} \varepsilon^{\prime \prime}{ }_{E G}(\omega)+\left(1-\frac{2 m_{E G}}{M w}\right) \varepsilon^{\prime \prime}{ }_{M w \rightarrow \infty}(\omega)
$$

where $m_{E G}$ is the mass of the units involved in the fluctuations of the end-group dipoles $\left(m_{E G} \approx m_{G P E}=150 \mathrm{~g} / \mathrm{mol}\right)$. Then, to evaluate both components, $\varepsilon{ }^{\prime}{ }_{\mathrm{EG}}(\omega)$ and $\varepsilon{ }^{\prime}{ }_{\mathrm{Mw} \rightarrow \infty}$ $(\omega)$, the $\beta$-relaxation data of two samples of different weight-average molecular weights $\left(\mathrm{M}_{\mathrm{w}}\right)$ were used. The resulting individual contributions obtained for a $L_{S R}(A)$ sample with $\mathrm{M}_{\mathrm{w}}=2.2 \mathrm{~kg} / \mathrm{mol}$ are shown in Figure 5a.
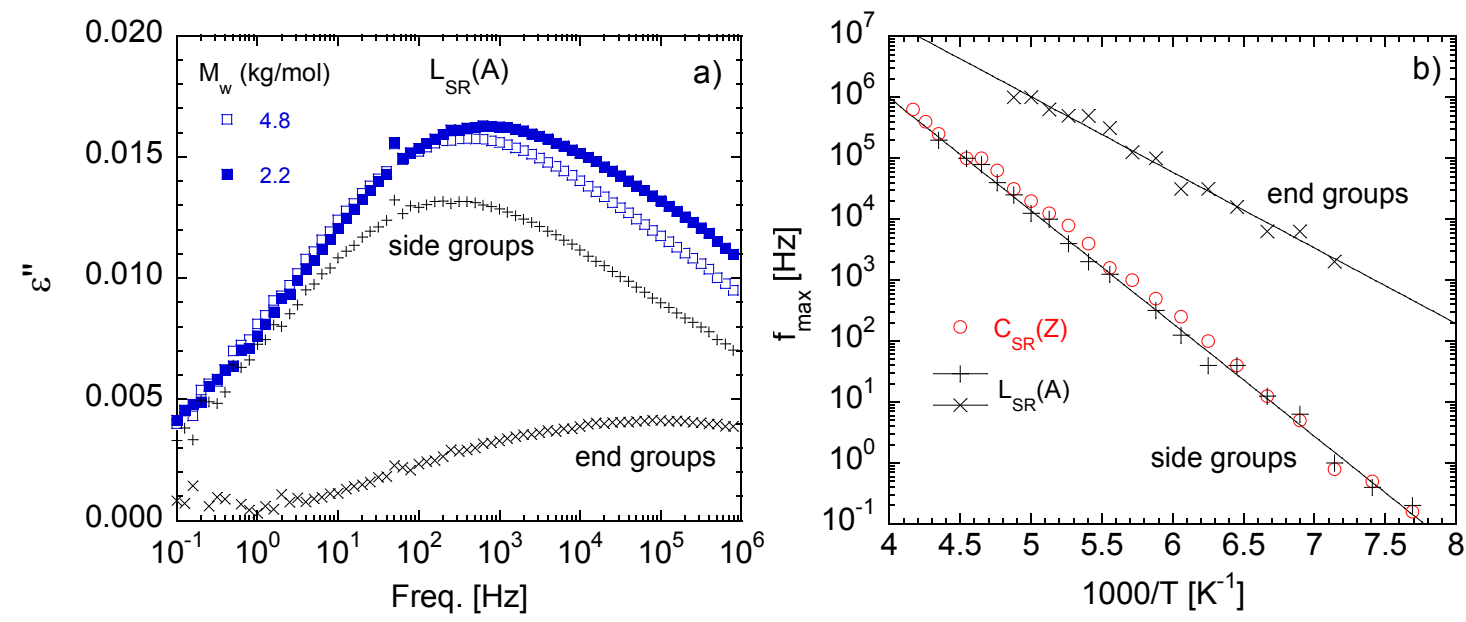
Figure 5. a) Frequency dependence of the $\varepsilon$ " for the $\beta$-relaxation of $L_{S R}(A)$ of two molecular weights. $(+)$ and $(\mathrm{x})$ represent the resolved contributions originating from side groups and end groups, respectively, of the low molecular weight $\mathrm{L}_{\mathrm{SR}}(\mathrm{A})$ sample. b) Arrhenius plot of the peak frequencies of both contributions for $L_{S R}(A)$ and of the whole $\beta$-relaxation peak frequency for $\mathrm{C}_{\mathrm{SR}}(\mathrm{Z})$.

The peak frequency of $\varepsilon^{\prime \prime}{ }_{E G}(\omega)$ and $\varepsilon^{\prime \prime}{ }_{M w \rightarrow \infty}(\omega)$ as a function of the inverse temperature are shown in an Arrhenius plot in Figure 5b. For both contributions we found Arrhenius temperature dependence, yielding activation energy $\left(E_{a}\right)$ values of 35.4 $\mathrm{kJ} / \mathrm{mol}$ (prefactor $=2.5 \times 10^{13} \mathrm{~Hz}$ ) and $23.8 \mathrm{~kJ} / \mathrm{mol}\left(\right.$ prefactor $=1.6 \times 10^{12} \mathrm{~Hz}$ ) for the motions of side groups and end groups, respectively. Both relaxation components are quite broad, which indicates a broad distribution of relaxation times and, consequently, a broad distribution of activation energies. The full width at half maximum of the distribution of activation energies $\left(F W H M_{E a}\right)$ can be approximately calculated from that of the experimental curves $\left(F W H M_{\varepsilon^{\prime \prime}}\right)$ as:

$$
F W H M_{E a}=k_{B} T\left(F W H M_{\varepsilon^{\prime \prime}}-1.14\right) \ln 10
$$

where the value of 1.14 decades comes from the width of the loss peak for a single relaxation time (see Supplementary Information). Using this approach, the $F W H M_{E a}$ values are $46 \%$ (of the average $\mathrm{E}_{\mathrm{a}}$ ) for the side-group motions and $66 \%$ for the endgroup motions in the $\mathrm{L}_{\mathrm{SR}}(\mathrm{A})$ series.

Figure 6 shows the frequency dependence of the $\varepsilon$ " for $C_{S R}(Z)$ and $L_{S R}(Z)$ of two molecular weights at $170 \mathrm{~K}$. It is interesting to note that the peak position for $\mathrm{C}_{\mathrm{SR}}(\mathrm{Z})$ 
samples is similar to that determined for the side-group contribution in the $L_{S R}(A)$ series, which is confirmed in the Arrhenius plot of Figure $5 b$ by the good superposition of the peak frequency data with that of the $\varepsilon{ }^{\prime}{ }_{M w \rightarrow \infty}(\omega)$. In addition, both cyclic samples show differences concerning the peak intensity and the relaxation broadening. The smaller ring shows reduction of intensity and broader relaxation compared to the larger ring. The $F W H M_{E a}$ values are $56 \%$ for the smaller ring and $53 \%$ for larger ring. These results suggest that reducing the ring size can cause additional topological constrains in the local motion responsible for the $\beta$-relaxation.

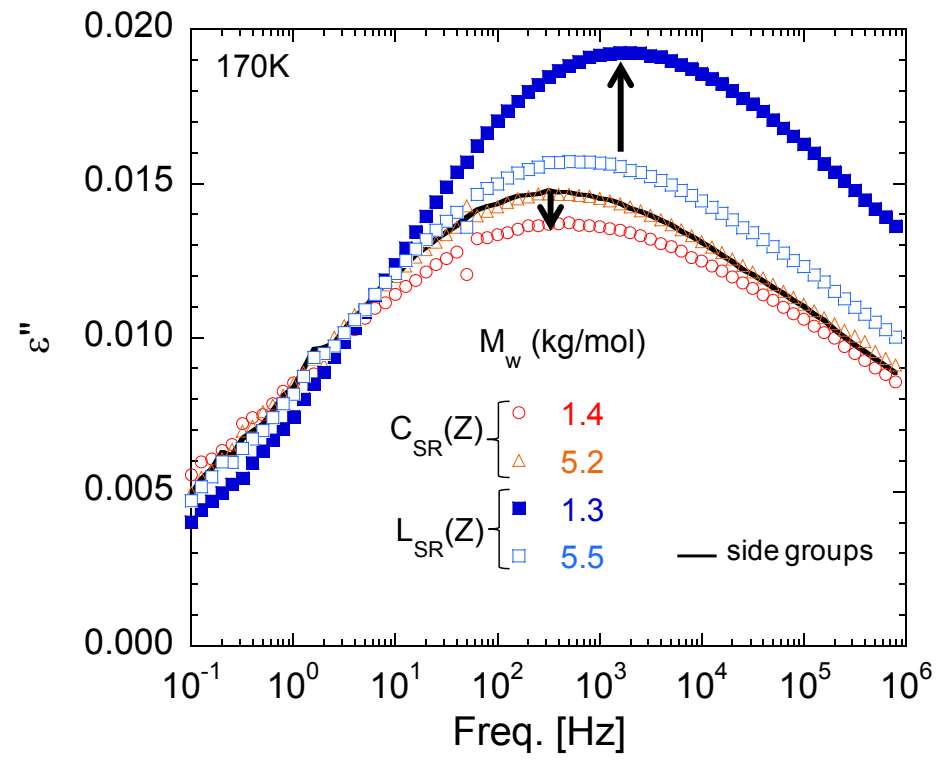

Figure 6. Frequency dependence of the $\varepsilon$ " for the $\beta$-relaxation of cyclic and linear PGPE samples of different molecular weights. Solid line shows the side-group contribution obtained for $\mathrm{L}_{\mathrm{SR}}(\mathrm{Z})$ of $\mathrm{M}_{\mathrm{w}}=5.5 \mathrm{~kg} / \mathrm{mol}$. Arrows indicate decreasing molecular weight. 
The side-group contribution to the $\beta$-relaxation in the $\mathrm{L}_{\mathrm{SR}}(\mathrm{Z})$ series was also evaluated by using the Equation 2 and the method described above. Interestingly, the resulting side-group contribution for $\mathrm{L}_{\mathrm{SR}}(\mathrm{Z})$ with $\mathrm{M}_{\mathrm{w}}=5.5 \mathrm{~kg} / \mathrm{mol}$ (solid line, Figure 6) overlaps the data of $C_{S R}(Z)$ with $M_{w}=5.2 \mathrm{~kg} / \mathrm{mol}$, which suggests that the topology does not play a key role on the side-group local dynamics for sufficiently large rings.

When analyzing the effects of regiostructure on the shape of the side-group contribution to the $\beta$-relaxation, we observed that samples with a higher level of regio-regularities exhibit narrower loss peaks, being $F W H M_{E a} 46 \%$ for $\mathrm{L}_{\mathrm{SR}}(\mathrm{A})$ and $52 \%$ for $\mathrm{L}_{\mathrm{SR}}(\mathrm{Z})$. This result confirms the higher homogeneity of the molecular environment for isoregic structures.

\section{Dielectric relaxations at $T>T_{g}$ (chain modes)}

Figure 7 shows the dielectric relaxations for representative linear and cyclic samples at $305 \mathrm{~K} . \mathrm{L}_{\mathrm{SR}}(\mathrm{A})$ series clearly show the $\alpha$-relaxation and NM peaks, whereas $\mathrm{L}_{\mathrm{SR}}(\mathrm{Z})$ and $\mathrm{C}_{\mathrm{SR}}(\mathrm{Z})$ series "apparently" show only the $\alpha$-relaxation peak. The NM peak in isoregic chains is originating from the end-to-end vector $\left(\vec{R}_{e-e}\right)$ fluctuations, being the resultant dipole moment $\vec{\mu}_{N M} \propto \vec{R}_{e-e}$ (Scheme 3a). Consequently, in this case, the NM relaxation reflects the whole chain dynamics. Based on topological considerations, for isoregic rings, it should be expected that $\vec{\mu}_{N M}=0$ (Scheme 3b). However, for aregic chains (case of $\mathrm{L}_{\mathrm{SR}}(\mathrm{Z})$ and $\left.\mathrm{C}_{\mathrm{SR}}(\mathrm{Z})\right)$, analysis of the low frequency part of the dielectric losses is more complicated since short-wavelength chain motions would contribute to the dielectric 
relaxation. Note that in this case the short-wavelength chain dipole moment $\left(\vec{\mu}_{C h M}\right)$ would not be proportional to $\vec{R}_{e-e}$ (Schemes $3 \mathrm{c}$ and $\left.3 \mathrm{~d}\right)$.

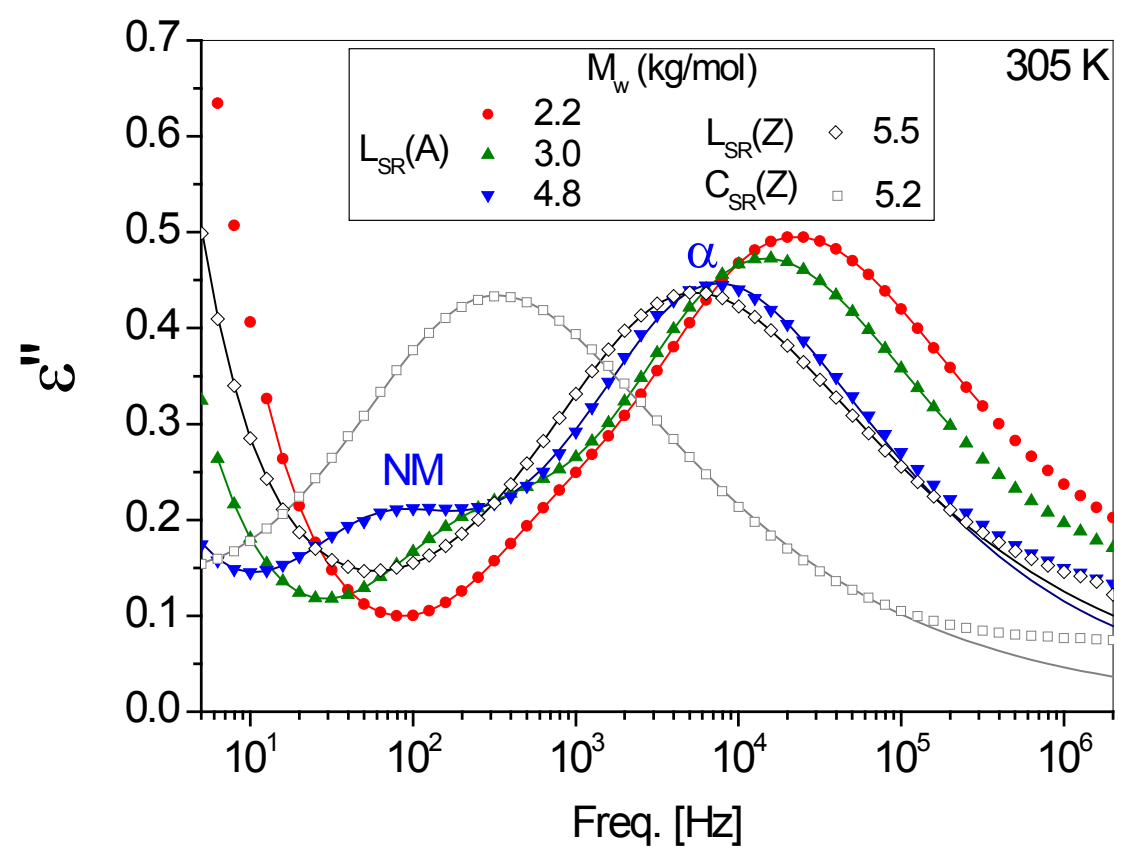

Figure 7. Frequency dependence of the $\varepsilon$ " for representative cyclic and linear PGPE samples at $305 \mathrm{~K}$. Solid lines are fitting curves (see the text below).

a)

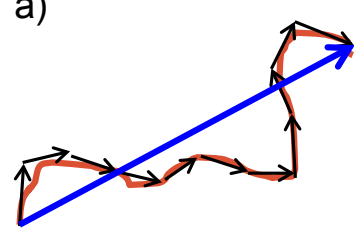

$\vec{\mu}_{N M} \propto \vec{R}_{e-e}$

c)

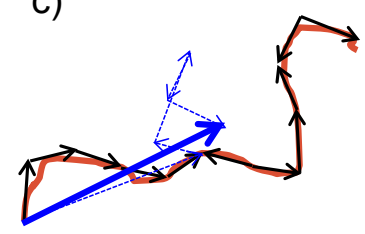

$\vec{\mu}_{C h M} \not c \vec{R}_{e-e}$ b)

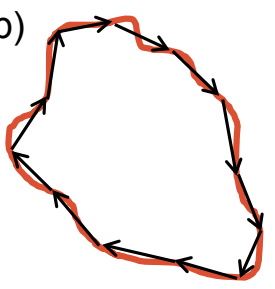

$\vec{\mu}_{\mathrm{NM}}=0$

d)

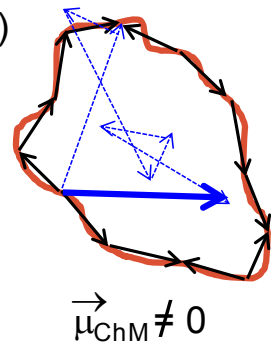


Scheme 3. Cartoon illustrating the resultant dipole moment vector $(\vec{\mu})$ for isoregic (a, b) and aregic (c, d) chains with linear and cyclic topologies.

As observed in Figure 7, the NM peak for $\mathrm{L}_{\mathrm{SR}}(\mathrm{A}) \mathrm{M}_{\mathrm{w}}=4.8 \mathrm{~kg} / \mathrm{mol}$ is well separated from that of the $\alpha$-relaxation. To fit the data, the dielectric spectrum was analyzed by using a combination of a NM relaxation function, according to the Rouse model with non-exponential modes, ${ }^{39}$ and a Havriliak-Negami $(\mathrm{HN})^{40}$ function describing the $\alpha$ relaxation (see details in the Supplementary Information). To limit the number of fitting parameters, we fixed the shape of the $\mathrm{HN}$ function to that corresponding to a Kohlrausch-Williams-Watts function in the time domain $(\mathrm{HN}-\mathrm{KWW}){ }^{41} \mathrm{~A}$ dc conductivity contribution was also included in the fitting equation. To minimize the contributions of the $\beta$-relaxation in the fit, the data was limited up to frequencies 10 times higher than that of the main peak. The obtained values of the fitting parameters are reported in Table 5.

Table 5. Fitting parameters of dielectric relaxation data at $305 \mathrm{~K}$ shown in Figure 7.

\begin{tabular}{|c|c|c|c|c|c|}
\hline & & $\mathbf{L}_{\mathrm{SR}}(\mathrm{A})$ & & $\mathbf{L}_{\mathrm{SR}}(\mathrm{Z})$ & $\mathrm{C}_{\mathrm{SR}}(\mathrm{Z})$ \\
\hline $\mathrm{M}_{\mathrm{w}}(\mathrm{kg} / \mathrm{mol})$ & 2.2 & 3.0 & 4.8 & 5.5 & 5.2 \\
\hline$\Delta \varepsilon_{\mathrm{NM}}$ & 0.34 & 0.39 & 0.44 & 0.27 & 0.21 \\
\hline$\tau_{\mathrm{NM}}(\mathrm{s})$ & $1.6 \times 10^{-4}$ & $7.1 \times 10^{-4}$ & $2.7 \times 10^{-3}$ & $2.4 \times 10^{-3}$ & $1.5 \times 10^{-2}$ \\
\hline$\alpha_{\mathrm{NM}}$ & $0.86^{*}$ & $0.86^{*}$ & 0.86 & 0.60 & 0.73 \\
\hline$\Delta \varepsilon_{\alpha}$ & 1.90 & 1.84 & 1.70 & 1.86 & 1.83 \\
\hline$\tau_{\alpha}(\mathrm{s})$ & $8.3 \times 10^{-6}$ & $1.4 \times 10^{-5}$ & $2.6 \times 10^{-5}$ & $2.8 \times 10^{-5^{*}}$ & $4.4 \times 10^{-4^{*}}$ \\
\hline$\alpha$ & $0.74^{*}$ & $0.74^{*}$ & 0.74 & 0.70 & 0.70 \\
\hline
\end{tabular}


$\Delta \varepsilon_{\mathrm{NM}}$ : dielectric relaxation strength of the NM. $\tau_{\mathrm{NM}}$ : peak relaxation time of the NM. $\alpha_{\mathrm{NM}}$ : shape parameter of the NM. $\Delta \varepsilon_{\alpha:}$ dielectric relaxation strength of the $\alpha$-relaxation. $\tau_{\alpha}$ : peak relaxation time of the $\alpha$-relaxation. $\alpha$ : shape parameter of the $\alpha$-relaxation. $\left(^{*}\right)$ : parameters that were fixed in the fitting procedure.

To fit the data of $\mathrm{L}_{\mathrm{SR}}(\mathrm{A})$ samples with $\mathrm{M}_{\mathrm{w}}=2.2$ and $3.0 \mathrm{~kg} / \mathrm{mol}$, where the $\mathrm{NM}$ is not well separated from the alpha relaxation, the parameters determining the shape of the $\alpha$ relaxation $(\alpha=0.74$ and $\gamma=0.56)$ and the non-exponentiality of the individual Rouse modes $\left(\alpha_{N M}=0.86\right)$ were fixed to those obtained for $L_{S R}(A)$ with $M_{w}=4.8 \mathrm{~kg} / \mathrm{mol}$, and only the relaxation times and the relaxation strengths $(\Delta \varepsilon)$ of the two processes were allow to vary. The obtained relaxation time values (Table 5) can be described by the following law:

$$
\frac{\tau_{\mathrm{NM}}}{\tau_{\alpha}}=5\left[M_{w} /(\mathrm{kg} / \mathrm{mol})\right]^{2}
$$

in good agreement with the Rouse model.

Figure 8 shows the $\mathrm{M}_{\mathrm{w}}$ dependence of the relaxation strengths $\Delta \varepsilon_{\mathrm{NM}}$ and $\Delta \varepsilon_{\alpha}$. The data show that $\Delta \varepsilon_{\mathrm{NM}}$ slightly decreases with decreasing $\mathrm{M}_{\mathrm{w}}$ for $\mathrm{L}_{\mathrm{SR}}(\mathrm{A})$ series. In principle, end-group dipoles are not expected to contribute to the NM, and therefore the observed behavior can be explained by the increasing concentration of end-groups with decreasing $\mathrm{M}_{\mathrm{w}}$. On the contrary, end groups do contribute to the $\alpha$-relaxation, which would explain the observed increase of $\Delta \varepsilon_{\alpha}$ with decreasing $\mathrm{M}_{\mathrm{w}}$. 


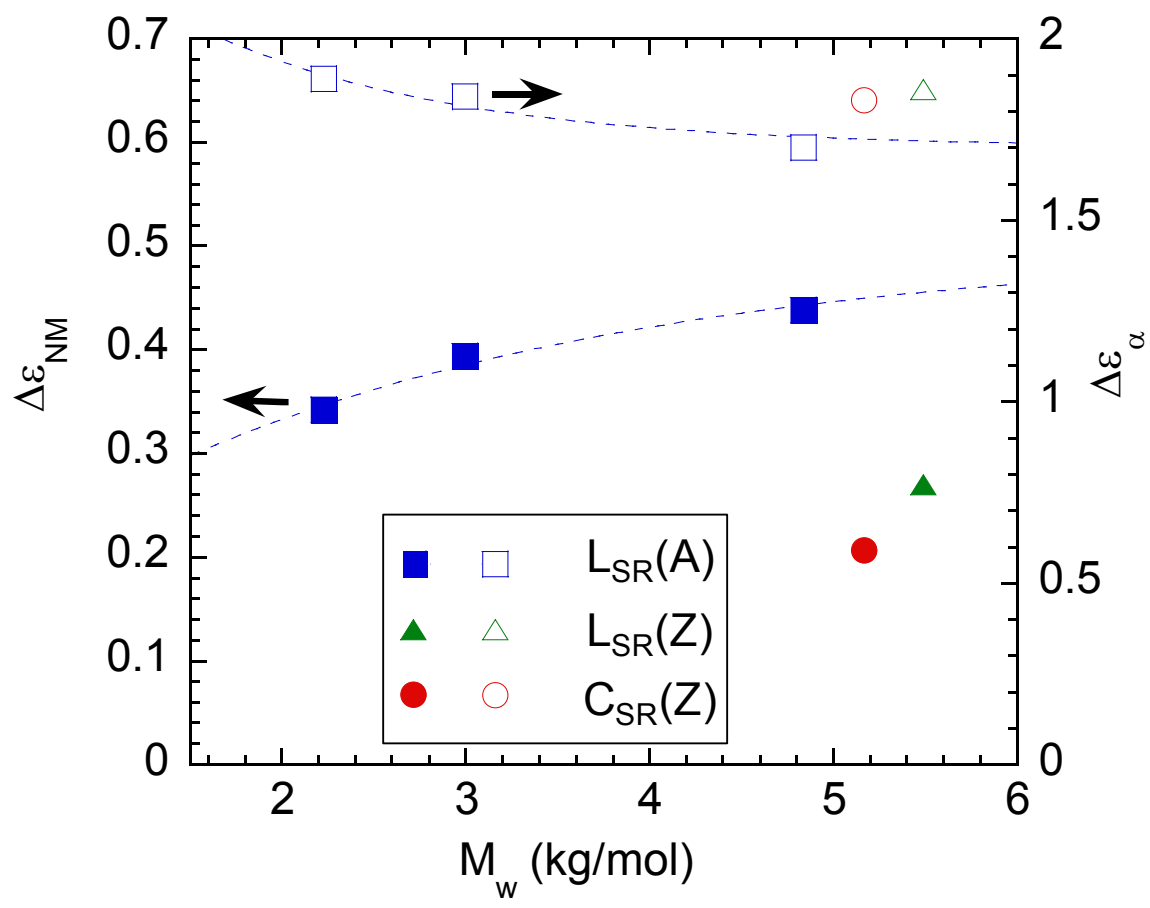

Figure 8. $\Delta \varepsilon_{\mathrm{NM}}$ (solid symbols) and $\Delta \varepsilon_{\alpha}$ (open symbols) for linear and cyclic PGPE samples as a function of the molecular weight.

In the aregic PGPE samples, either linear or cyclic, the presence of slow dielectric contributions from chain modes is not obvious. To confirm the presence of low frequency contributions to the dielectric relaxation peak, dielectric data at two temperatures are compared in Figure 9 for the highest molecular weight $\mathrm{L}_{\mathrm{SR}}(\mathrm{Z})$ and $\mathrm{C}_{\mathrm{SR}}(\mathrm{Z})$ samples of each series. This comparison is justified by the fact that the relaxation times of the chain modes and those of the $\alpha$-relaxation exhibit different temperature dependence, becoming more separated with increasing temperature (see Figure $4 \mathrm{~b})$. The comparison in both samples show a noticeably broadening of the relaxation peaks at the low frequency side for the high-temperature dielectric-loss data, which can be explained by the contribution of short-wavelength chain modes (Schemes $3 \mathrm{c}$ and $3 \mathrm{~d})$. 

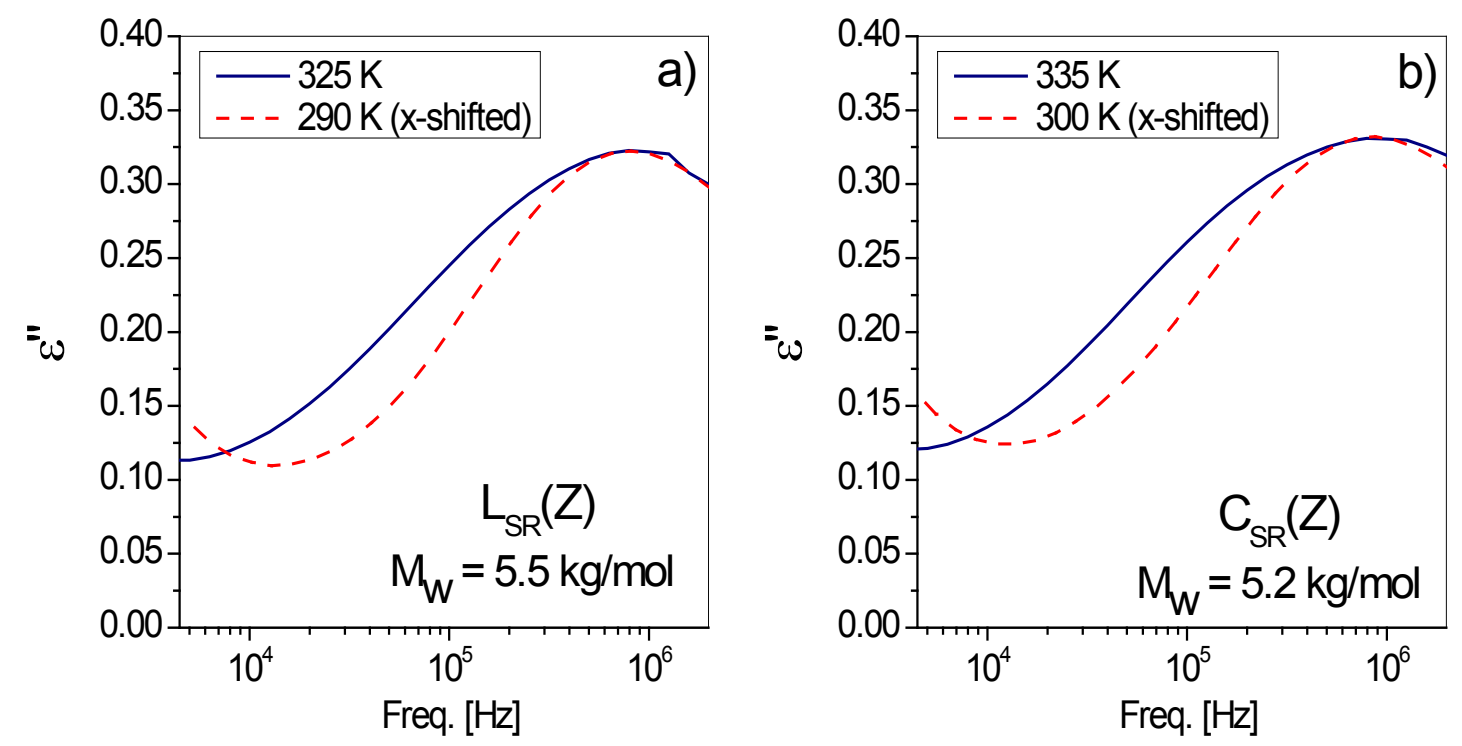

Figure 9. Comparison of the frequency dependence of the $\varepsilon$ "' at two temperatures exhibiting the presence of slow components associated with short-wavelength chain modes for aregic linear (a) and cyclic (b) PGPE samples. To superpose the peak maxima, low temperature data were shifted to high frequencies.

To quantify these slow contributions to the dielectric relaxation in the aregic polymers, the dielectric loss data of Figure 7 cannot be fitted with the same procedure as that used for the $\mathrm{L}_{\mathrm{SR}}(\mathrm{A})$ series because the NM contribution does not correspond to the end-toend vector fluctuations. Instead, the NM contribution in aregic samples was modeled by a HN-KWW function similar to that used for the $\alpha$-relaxation. To reduce the number of free fitting parameters, the peak $\alpha$-relaxation times were fixed to those obtained from the global dielectric losses. The obtained $\Delta \varepsilon_{\alpha}$ values for $\mathrm{L}_{\mathrm{SR}}(\mathrm{Z})$ and $\mathrm{C}_{\mathrm{SR}}(\mathrm{Z})$ (Table 5, Figure 8) were found to be similar to those of the isoregic samples, as expected. However, due to regio-irregularities in $\mathrm{L}_{\mathrm{SR}}(\mathrm{Z})$ and $\mathrm{C}_{\mathrm{SR}}(\mathrm{Z})$, their $\Delta \varepsilon_{\mathrm{NM}}$ values are nearly the half compared to that of $\mathrm{L}_{\mathrm{SR}}(\mathrm{A})$ with similar $\mathrm{M}_{\mathrm{w}}$ (Figure 8 ). It is worthy to note that 
the relaxation time of the slow components in aregic samples cannot be identified with the Rouse time for non-entangled linear chains, but it would be representative of shorter wavelength chain fluctuations.

\section{Dielectric relaxations at $T>T_{g}(\alpha-$-relaxation)}

The maxima of the whole relaxation peaks correspond well to the $\alpha$-relaxation times (Figure 7). We have determined the temperature dependence of the relaxation times $\left(\tau_{\max }\right)$ by selecting the peak maxima for the different samples. The results, plotted in Figure 10, were fitted to a Vogel-Fulcher-Tammann (VFT) equation:

$$
\tau(\mathrm{T})=\tau_{0} \exp \left(\frac{D T_{0}}{T-T_{0}}\right)
$$

where $\tau_{0}$ is the typical vibrational time (fixed to $\tau_{0}=1 \times 10^{-14} \mathrm{~s}$ ), $D$ is the parameter related to the so-called dynamic fragility (low D corresponds to high dynamic fragility and vice-versa) and $T_{0}$ is the so-called Vogel temperature, where the relaxation times would diverge. ${ }^{7}$ We found that $D=6.1$ for all linear samples, independently of the level of regicity and molecular weight, and $D=6.4$ for cyclic chains. These values are nearly the half of those found for polyethers containing aliphatic side groups. ${ }^{38}$

The reduction of the dynamic fragility found for cyclic PGPE (higher D value) compared to linear PGPE would support the interpretation provided in a recent study on the effects of cyclic chain topology on the $T_{g}$ depression in thin PS films, ${ }^{36}$ where the authors found much weaker thickness dependence of the $T_{g}$ for cyclic PS compared to 
linear PS. The significant reduction of the dynamic fragility for cyclic polymers would arise from the reduced configurational entropy of rings relative to linear chains. ${ }^{37}$

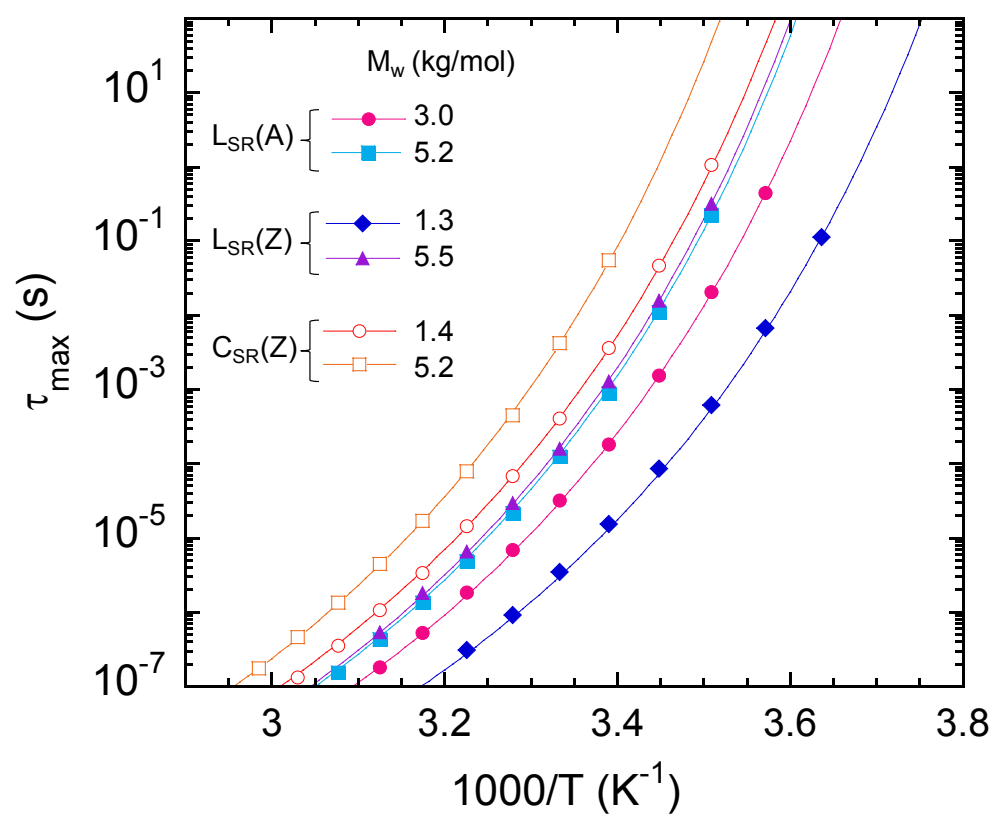

Figure 10. Temperature dependence of the $\alpha$-relaxation times for cyclic and linear PGPE samples. Solid lines are the fits obtained by means of the VFT equation (Equation 5).

The obtained $T_{0}$ and $\mathrm{D}$ values allow calculating the dynamic (dielectric) glass transition temperatures, $T_{g}^{B D S}$, as:

$$
\mathrm{T}_{\mathrm{g}}^{\mathrm{BDS}}=T_{0}\left[1+D / \ln \left(\frac{100 s}{\tau_{\infty}}\right)\right]
$$

where the relaxation time defining the dynamic glass transition is fixed to a value of 100s by convention. ${ }^{7}$ The obtained $T_{g}{ }^{B D S}$ values are compared with the calorimetric $T_{g}$ 
$\left(T_{g}{ }^{D S C}\right)$ values in Figure 3. Both data sets are in good agreement, although $T_{g}^{B D S}$ is systematically smaller than $T_{g}^{D S C}$ by $1-3 \mathrm{~K}$, likely due to the relatively higher heating rates of the DSC experiments compared to those involved in BDS.

\section{CONCLUSIONS}

The combination of BDS and the variety of well-characterized PGPE samples with different topology and microstructure provides a detailed analysis of the effects of these structural characteristics on the molecular dynamics at different length scales (side groups, segmental motions and chain dynamics). The unique structural signatures of linear and cyclic PGPE was clearly revealed in the local $\beta$-relaxation due to the significant end-group contributions to this process. Side-group dynamic contributions are not much affected either by microstructure or topology although small changes in the width of the distribution of activation energies are detected.

Cyclic chains show higher $T_{g}$ than linear chains of same molecular weight and microstructure. The molecular weight dependence of the $T_{g}$ for all linear PGPE samples can be described by the Kanig-Ueberreiter equation, irrespective of their level of regicity. These results are in agreement with the dynamic glass transition calculated from the temperature dependence of the $\alpha$-relaxation times. Moreover, dielectric results evidence that the dynamic fragility of cyclic chains is lower compared to that of linear chains, and that it is independent of both the regicity and the molecular weight.

Owing to regio-errors in cyclic chains, we could detect a low frequency component in the dielectric relaxation originating from short-wavelength internal ring motions. The 
dielectric relaxation strength in aregic samples is nearly the half of that found for the normal mode relaxation in linear isoregic polymers. In addition, the relaxation time of the low frequency component in aregic samples is shorter than that for a linear isoregic sample of similar $\mathrm{M}_{\mathrm{w}}$.

In conclusion, BDS is proved to be a powerful and sensitive tool not only to detect microstructural effects on the molecular dynamics, but also to investigate the molecular dynamics in cyclic polymers, which has not been sufficiently explored to date. In addition to the usual effects of cyclic topology on the glass transition temperature, we detect for first time effects of cyclic topology on the dynamic fragility.

\section{ASSOCIATED CONTENT}

\section{Supporting Information}

Experimental procedures and data analysis. This information is available free of charge via the Internet at http://pubs.acs.org/.

\section{AUTHOR INFORMATION}

\section{Corresponding Author}

*E-mail: fbarroso@ehu.eus.

\section{ACKNOWLEDGEMENTS}


We gratefully acknowledge support from MINECO (MAT2012-31088) and Basque Government (IT-654-13). The authors thank Isabel Asenjo-Sanz for her help in the chemistry synthesis laboratory, Prof. Jose A. Pomposo for fruitful discussions, and Dr. Antonio Veloso (POLYMAT) for MALDI-ToF MS analysis.

\section{REFERENCES}

(1) Yamamoto, T.; Tezuka, Y. Polym. Chem. 2011, 2, 1930-1941.

(2) Kirst, K. U.; Kremer, F.; Pakula, T.; Hollingshurst, J. Colloid Polym. Sci. 1994, 272 , $1420-1429$.

(3) Yamamoto, T.; Tezuka, Y. Soft Matter 2015, 11, 7458-7468.

(4) Semlyen, J. A., Cyclic Polymers. Second ed.; Kluwer Academic Publishers: New York, Boston, Dordrecht, London, Moscow, 2002.

(5) Richter, D.; Goo; Wischnewski, A. Soft Matter 2015, 11, 8535-8549.

(6) Tezuka, Y., Topological Polymer Chemistry. Progress of Cyclic Polymers in Syntheses, Properties and Functions. Word Scientific Publishing Co. Pte. Ltd.: 2013.

(7) Kremer, F.; Schönhals, A., Broadband Dielectric Spectroscopy. Springer-Verlag Berlin Heidelberg: 2003.

(8) Nam, S.; Leisen, J.; Breedveld, V.; Beckham, H. W. Polymer 2008, 49, 5467-5473.

(9) McKenna, G. B.; Hostetter, B. J.; Hadjichristidis, N.; Fetters, L. J.; Plazek, D. J. Macromolecules 1989, 22, 1834-1852.

(10) Doi, Y.; Matsubara, K.; Ohta, Y.; Nakano, T.; Kawaguchi, D.; Takahashi, Y.; Takano, A.; Matsushita, Y. Macromolecules 2015, 48, 3140-3147. 
(11) Gooßen, S.; Brás, A. R.; Krutyeva, M.; Sharp, M.; Falus, P.; Feoktystov, A.; Gasser, U.; Pyckhout-Hintzen, W.; Wischnewski, A.; Richter, D. Phys. Rev. Lett. 2014, $113,168302$.

(12) Clarson, S. J.; Dodgson, K.; Semlyen, J. A. Polymer 1985, 26, 930-934.

(13) Ronda, J. C.; Serra, A.; Mantecón, A.; Cádiz, V. Acta Polym. 1996, 47, 269-275.

(14) Adachi, K.; Kotaka, T. Prog. Polym. Sci. 1993, 18, 585-622.

(15) Watanabe, H. Prog. Polym. Sci. 1999, 24, 1253-1403.

(16) Roland, C. M.; Bero, C. A. Macromolecules 1996, 29, 7521-7526.

(17) Floudas, G.; Paraskeva, S.; Hadjichristidis, N.; Fytas, G.; Chu, B.; Semenov, A. N. J. Chem. Phys. 1997, 107, 5502-5509.

(18) Petychakis, L.; Floudas, G.; Fleischer, G. Europhys. Lett. 1997, 40, 685.

(19) Lund, R.; Barroso-Bujans, F.; Slimani, M. Z.; Moreno, A. J.; Willner, L.; Richter, D.; Alegría, A.; Colmenero, J. Macromolecules 2013, 46, 7477-7487.

(20) Gerstl, C.; Schneider, G. J.; Pyckhout-Hintzen, W.; Allgaier, J.; Richter, D.; Alegría, A.; Colmenero, J. Macromolecules 2010, 43, 4968-4977.

(21) Childers, M. I.; Longo, J. M.; Van Zee, N. J.; LaPointe, A. M.; Coates, G. W. Chem. Rev. 2014, 114, 8129-8152.

(22) Asenjo-Sanz, I.; Veloso, A.; Miranda, J. I.; Pomposo, J. A.; Barroso-Bujans, F. Polym. Chem. 2014, 5, 6905-6908.

(23) Laurent, B. A.; Grayson, S. M. Chem. Soc. Rev. 2009, 38, 2202-2213.

(24) Morinaga, H.; Ochiai, B.; Endo, T. Macromolecules 2007, 40, 6014-6016.

(25) Ronda, J. C.; Serra, A.; Mantecón, A.; Cádiz, V. Polymer 1995, 36, 471-478.

(26) Tezuka, Y.; Ohtsuka, T.; Adachi, K.; Komiya, R.; Ohno, N.; Okui, N. Macromol. Rapid Commun. 2008, 29, 1237-1241. 
(27) Shin, E. J.; Jeong, W.; Brown, H. A.; Koo, B. J.; Hedrick, J. L.; Waymouth, R. M. Macromolecules 2011, 44, 2773-2779.

, M. E.; Lorenzo, A. T.; Muller, A. J.; Hoskins, J. N.; Grayson, S. M. Macromolecules 2011, 44, 1742-1746.

(29) Ueberreiter, K.; Kanig, G. J. Colloid Sci. 1952, 7, 569-583.

(30) Santangelo, P. G.; Roland, C. M.; Chang, T.; Cho, D.; Roovers, J. Macromolecules 2001, 34, 9002-9005.

(31) Alberty, K. A.; Hogen-Esch, T. E.; Carlotti, S. Macromol. Chem. Phys. 2005, 206, $1035-1042$.

(32) Gan, Y.; Dong, D.; Hogen-Esch, T. E. Macromolecules 1995, 28, 383-385.

(33) Blackburn, S. C.; Tillman, E. S. Macromol. Chem. Phys. 2015, 216, 1282-1290.

(34) Clarson, S. J.; Semlyen, J. A.; Dodgson, K. Polymer 1991, 32, 2823-2827.

(35) Hossain, M. D.; Lu, D.; Jia, Z.; Monteiro, M. J. ACS Macro Lett. 2014, 3, 12541257.

(36) Zhang, L.; Elupula, R.; Grayson, S. M.; Torkelson, J. M. Macromolecules 2015, 10.1021/acs.macromol.5b02474.

(37) Di Marzio, E. A.; Guttman, C. M. Macromolecules 1987, 20, 1403-1407.

(38) Yamane, M.; Hirose, Y.; Adachi, K. Macromolecules 2005, 38, 10686-10693.

(39) Arrese-Igor, S.; Alegría, A.; Colmenero, J. Phys. Rev. Lett. 2014, 113, 078302.

(40) Havriliak, S.; Negami, S. J. Polym. Sci., Part C: Polymer Symposia 1966, 14, 99117.

(41) Zorn, R.; Monkenbusch, M.; Richter, D.; Alegría, A.; Colmenero, J.; Farago, B. J. Chem. Phys. 2006, 125, 154904. 
For Table of Contents use only

Dielectric Relaxations in Poly(Glycidyl Phenyl Ether): Effects of Microstructure and Cyclic Topology

Thomas Gambino, Antxon Martínez de Ilarduya, Angel Alegría, and Fabienne BarrosoBujans

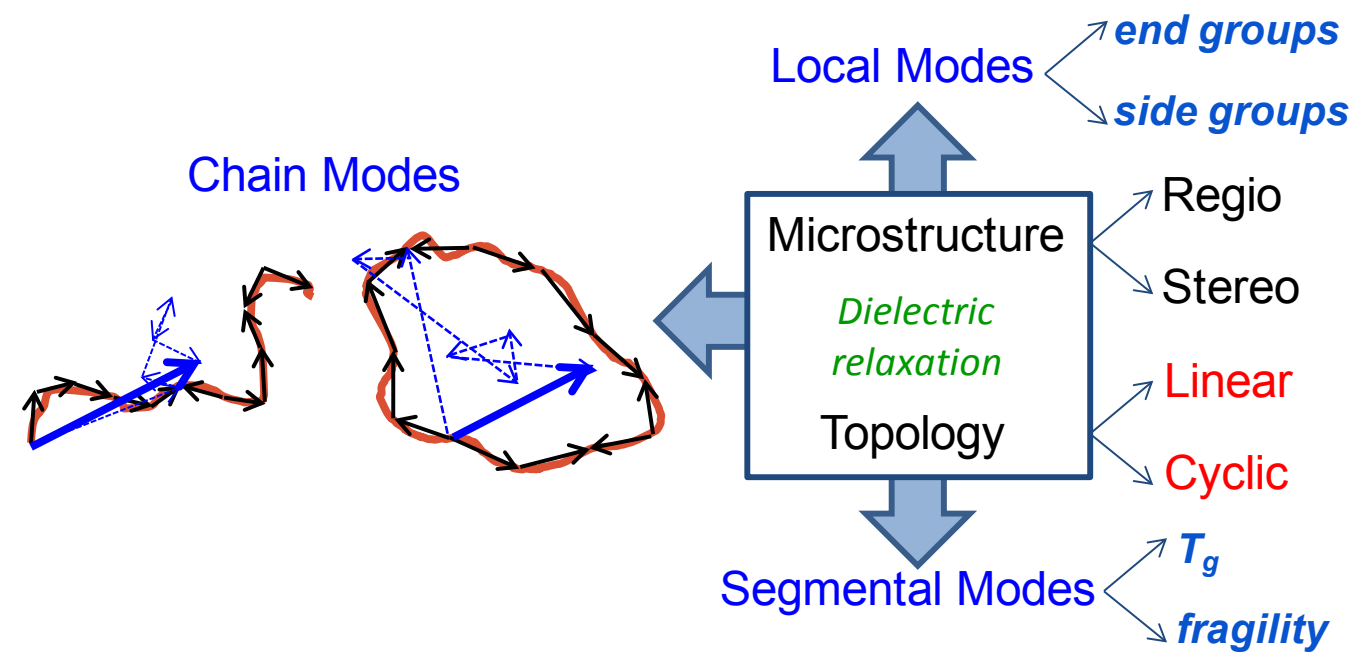

